\title{
Underwater light climate and wavelength dependence of microalgae photosynthetic parameters in a temperate sea
}

\author{
Monica Michel-Rodriguez ${ }^{\text {Corresp., } 1}$, Sebastien Lefebvre ${ }^{1}$, Muriel Crouvoisier $^{1}$, Xavier Meriaux $^{2}$, Fabrice Lizon $^{\text {Corresp. } 1}$ \\ 1 Univ. Lille, CNRS, Univ. Littoral Côte d'Opale, UMR 8187 LOG, Laboratoire d'Océanologie et de Géosciences, Lille, France \\ 2 Univ. Littoral Côte d'Opale, CNRS, Univ. Lille, UMR 8187 - LOG - Laboratoire d'Océanologie et de Géosciences, Wimereux, France \\ Corresponding Authors: Monica Michel-Rodriguez, Fabrice Lizon \\ Email address: monica.michel-rodriguez@univ-lille.fr, fabrice.lizon@univ-lille.fr
}

Studying how natural phytoplankton adjust their photosynthetic properties to the quantity and quality of underwater light (i.e. light climate) is essential to understand primary production. A wavelength-dependent photoacclimation strategy was assessed using a multi-color pulse-amplitude-modulation chlorophyll fluorometer for phytoplankton samples collected in the spring at 19 locations across the English Channel. The functional absorption cross section of photosystem II, photosynthetic electron transport $\left(\mathrm{PET}_{\lambda}\right)$ parameters and non-photochemical quenching were analyzed using an original approach with a sequence of three statistical analyses. Linear mixed-effects models using wavelength as a longitudinal variable were first applied to distinguish the fixed effect of the population from the random effect of individuals. Population and individual trends of wavelength-dependent $\mathrm{PET}_{\lambda}$ parameters were consistent with photosynthesis and photoacclimation theories. The natural phytoplankton communities studied were in a photoprotective state for blue wavelengths (440 and $480 \mathrm{~nm}$ ), but not for other wavelengths (green $(540 \mathrm{~nm})$, amber $(590 \mathrm{~nm})$ and light red $(625 \mathrm{~nm})$ ). Populationdetrended $\mathrm{PET}_{\lambda}$ values were then used in multivariate analyses (partial triadic analysis and redundancy analysis) to study ecological implications of $\mathrm{PET}_{\lambda}$ dynamics among water masses. Two wavelength ratios based on the microalgae saturation parameter $E_{k}$ (in relative and absolute units), related to the hydrodynamic regime and underwater light climate, clearly confirmed the physiological state of microalgae. They also illustrate more accurately that natural phytoplankton communities can implement photoacclimation processes that are influenced by in situ light quality during the daylight cycle in temporarily and weakly stratified water. Ecological implications and consequences of $\mathrm{PET}_{\lambda}$ are discussed in the context of turbulent coastal ecosystems. 


\section{Underwater light climate and wavelength dependence of 2 microalgae photosynthetic parameters in a temperate sea}

3 Monica Michel-Rodriguez ${ }^{1}$, Sébastien Lefebvre ${ }^{1}$, Muriel Crouvoisier ${ }^{1}$, Xavier Meriaux ${ }^{2}$, Fabrice

4 Lizon $^{1}$

$5{ }^{1}$ Univ. Lille, CNRS, Univ. Littoral Côte d'Opale, UMR 8187 LOG, Laboratoire d'Océanologie et

6 de Géosciences, F-59000 Lille, France

$7 \quad 2$ Univ. Littoral Côte d'Opale, CNRS, Univ. LilleUMR 8187 LOG, Laboratoire d'Océanologie et 8 de Géosciences, F-62930, Wimereux, France

10 Corresponding Author:

11 Monica Michel-Rodriguez and Fabrice Lizon ${ }^{1}$

12 Laboratoire d'Océanologie et de Géosciences - UMR 8187 LOG Lille/CNRS/ULCO, 28 avenue

13 Foch, 62930 Wimereux, France

14 Email address: monica.michel-rodriguez@univ-lille.fr ; fabrice.lizon@univ-lille.fr

15

16

17 
19 Underwater light climate and wavelength dependence of microalgae photosynthetic parameters in a temperate sea

Michel-Rodriguez ${ }^{1}$ M., Lefebvre ${ }^{1}$ S., Crouvoisier ${ }^{1}$ M., Meriaux ${ }^{2}$ X. and Lizon ${ }^{1}$ F.

${ }^{1}$ Univ. Lille, CNRS, Univ. Littoral Côte d'Opale, UMR 8187 LOG, Laboratoire d'Océanologie et de Géosciences, F-59000 Lille, France

${ }^{2}$ Univ. Littoral Côte d'Opale, CNRS, Univ. Lille UMR 8187 LOG, Laboratoire d'Océanologie et de Géosciences, F-62930, Wimereux, France

Corresponding Authors :

Michel-Rodriguez, M. \& Lizon, F.

Laboratoire d'Océanologie et de Géosciences - UMR 8187 LOG Lille/CNRS/ULCO,

3128 avenue Foch, 62930 Wimereux, France

Email address: monica.michel-rodriguez@univ-lille.fr; fabrice.lizon@univ-lille.fr

\section{Abstract}

Studying how natural phytoplankton adjust their photosynthetic properties to the quantity and quality of underwater light (i.e. light climate) is essential to understand primary production. A wavelength-dependent photoacclimation strategy was assessed using a multi-color pulseamplitude-modulation chlorophyll fluorometer for phytoplankton samples collected in the spring at 19 locations across the English Channel. The functional absorption cross section of photosystem II, photosynthetic electron transport $\left(\mathrm{PET}_{\lambda}\right)$ parameters and non-photochemical quenching were analyzed using an original approach with a sequence of three statistical analyses. Linear mixedeffects models using wavelength as a longitudinal variable were first applied to distinguish the fixed effect of the population from the random effect of individuals. Population and individual trends of wavelength-dependent $\mathrm{PET}_{\lambda}$ parameters were consistent with photosynthesis and photoacclimation theories. The natural phytoplankton communities studied were in a photoprotective state for blue wavelengths (440 and $480 \mathrm{~nm}$ ), but not for other wavelengths (green $(540 \mathrm{~nm})$, amber $(590 \mathrm{~nm})$ and light red $(625 \mathrm{~nm}))$. Population-detrended $\mathrm{PET}_{\lambda}$ values were then used in multivariate analyses (partial triadic analysis and redundancy analysis) to study ecological 
50 microalgae saturation parameter $\mathrm{E}_{\mathrm{k}}$ (in relative and absolute units), related to the hydrodynamic 51 regime and underwater light climate, clearly confirmed the physiological state of microalgae. They 52 also illustrate more accurately that natural phytoplankton communities can implement 53 photoacclimation processes that are influenced by in situ light quality during the daylight cycle in 54 temporarily and weakly stratified water. Ecological implications and consequences of $\mathrm{PET}_{\lambda}$ are discussed in the context of turbulent coastal ecosystems.

\section{Introduction}

In nature, phytoplankton must respond to multiple variations in the quantity and quality of light (i.e. light climate) at different temporal (from day to year) and spatial (from environmental coastal gradients to large hydrological structures) scales (MacIntyre et al., 2000; Dubinsky \& Schofield, 2010). It is well known that microalgae have a strong ability to photoregulate, photoacclimate and photoadapt to these variations, as demonstrated by many articles and reviews (e.g. Anning et al., 2000; Dubinsky \& Stambler, 2009). Kirk (2011) reviewed these photobiological processes and defined them as ecological strategies, highlighting the role of the light climate. Microalgae adapt to variability in the light climate through phylogenetic adaptations and ontogenetic acclimation. Evidence of phylogenetic adaptation has existed since Engelmann (1883) developed chromatic adaptation theory and has experienced some controversy (e.g. Bidigare et al., 1990; Falkowski \& LaRoche, 1991). Pigment composition and thus cell absorption spectra, which determine light-use efficiency, have evolved to match the spectral characteristics of the prevailing light in a water mass. Ontogenetic acclimation in response to light conditions at the time of cell growth and development may modify a species' pigment composition and photosynthetic functioning, thus significantly influencing wavelength-dependent light absorption. Physiological state and photosynthetic properties of phytoplankton can be studied by using photosynthetic light-response (PE) curves to estimate photosynthetic activity as light levels increase (Platt \& Jassby, 1976). Light-use efficiency (initial slope, $\alpha$, see Table 1 for symbols, abbreviations and definitions related to photosynthetic parameters and variable fluorescence measures) and maximum photosynthetic rate $\left(\rho_{\max }\right)$ parameters of PE curves are the two main parameters traditionally used to investigate biophysical, biochemical and metabolic processes that influence photosynthesis (MacIntyre et al., 2002; Falkowski \& Raven, 2007) in response to variations in the light climate. Understanding 
80 better the response of cells to potential light stress in surface water also requires studying the 81 distribution of light energy between the photochemical and non-photochemical pathways, which 82 includes thermal dissipation of excess absorbed light energy (Lavaud, 2007). These processes are 83 well documented for diatoms (Brunet \& Lavaud, 2010) and can be studied easily by quantifying 84 the light response (E from light Energy) of non-photochemical quenching (NPQ, Serôdio \& 85 Lavaud, 2011).

86

87 88

Measuring the light absorption capacity of microalgae is essential to estimate the survival and production capacity of cells, and for ecologists to assess photosynthetic activity and primary production. To this end, a new generation of commercial fluorometers (e.g. multi-color pulseamplitude-modulation (PAM) chlorophyll fluorometer (Heinz Walz GmbH, Germany), mini-FIRe (Gorbunov et al., 2020)) has been designed to study wavelength dependence of photosynthetic electron transport $\left(\mathrm{PET}_{\lambda}\right)$ in relation to the light absorption capacity and/or to focus on general photosynthetic activity of phytoplankton groups in a given ecosystem (e.g. a fast repetition rate fluorometer (Chelsea Technologies Group Ltd., United Kingdom), FFL-40 (Photon Systems Instruments, Czech Republic). In limnology and oceanography, nearly all studies that included in vivo chlorophyll $a$ (Chla) variable fluorescence have measured direct light absorption capacity and photosynthesis for only one color of light. In most PAM techniques blue and red wavelengths ( \pm 470 and $650 \mathrm{~nm}$ ) were typically used for measuring lights. In most recent FRRf studies, blue wavelength $( \pm 450 \mathrm{~nm})$ was generally used because it is one of the main spectral bands absorbed by Chla (400-500 nm), the most common and abundant photosynthetic pigment, and the dominant color in the marine environment (Schreiber et al., 2012). One exception is the recent study of Houliez et al., (2017), who performed the first in situ measurements of light absorption capacity and photosynthetic yield with blue $(458 \mathrm{~nm})$ and amber $(593 \mathrm{~nm})$ lights in the Baltic Sea. However, since it focused on the specific problem of measuring fluorescence rise in cyanobacteria, its results cannot be generalized to other phytoplankton groups.

Many studies have shown that pigment absorbance by microalgae is strongly correlated with the spectral transmittance of water and its components (Hickman et al., 2010; Lawrenz \& Richardson, 2017). Colored dissolved organic matter (CDOM) and suspended particle concentrations can dramatically change the quantity and, especially, quality of light in coastal water (Kirk, 2011). To help Chla absorb light energy at different wavelengths, microalgae have a variety of accessory 
110 pigments. For example, the ecological success of diatoms is due to their pigment signature

111 (Falkowski \& Knoll, 2007), which includes Chla, Chlc and fucoxanthin (which expand the spectral

112 absorption band to $580 \mathrm{~nm}$ ), along with $\beta$-carotene and the xanthophylls involved in

113 photoprotection (Brunet \& Lavaud, 2010; Jeffrey et al., 2011). This diversity of pigments enables

114 brown algae, such as diatoms, to be more effective than green or red algae (Lavaud, 2007) in

115 turbulent systems or in the mixed layer of the coastal ocean. However, the photosynthetic

116 apparatus can acclimate to variations in light climate by changing cell pigment concentrations

117 and/or ratios (MacIntyre et al., 2002). This can change the shape of the light-absorption spectrum

118 and influence the efficiency of photosynthesis (Barlow et al., 2013, 2017). When light decreases,

119 pigment concentrations usually increase in cells during growth, with or without wavelength-

120 dependent changes in light absorption (Falkowski \& LaRoche, 1991). In addition, pigment

121 concentration can also increase due to an increase in the size and/or number of photosynthetic units

122 (i.e. antennas containing light-harvesting pigments) (Dubinsky \& Stambler, 2009) depending on

123 the phytoplankton group and ecosystem. Under high light conditions, cells increase the reaction

124 center number with a smaller antenna size, inducing higher values of $\rho_{\max }$. On the opposite, under

125 low light conditions, cells increase their antenna size, inducing higher values of $\alpha$. However, light

126 harvesting by cells is not always correlated with pigment concentration due to mutual shading of

127 the increasing density of pigment molecules (i.e. the "package effect" (Bidigare et al., 1990)).

128 In response to changes in light color, an effective photoacclimation mechanism was observed in 129 cyanobacteria that involves regulating "complementary chromatic adaptation" (CCA) (Kehoe \&

130 Gutu, 2006). CCA involves strong restructuring of photosynthetic antennas through pigment 131 concentrations, including pigment-binding antenna proteins. Diatoms have fewer flexible binding 132 proteins, such as fucoxanthin-chlorophyll a/c-binding antenna pigment-proteins complexe (FCPs),

133 than cyanobacteria with which to perform classic CCA; however, diatom fucoxanthin may have

134 different positions in the light-harvesting complex proteins of the antenna, which provide different

135 levels of energy transfer as a function of light quality (Premvardhan et al., 2008). Through pigment

136 analyses, Brunet et al., (2014) showed that spectral composition strongly influences the balance

137 between light harvesting and photoprotective capacity of diatoms. Valle et al., (2014) and

138 Schellenberger Costa et al., (2013a) observed that the energy transfer efficiency of light-harvesting

139 pigments is wavelength-dependent and that diatoms' ability to activate photoprotection and repair

140 a photodamaged photosystem II (PSII) effectively depends on light quality. Orefice et al., (2016) 
141 observed that variations in the light spectrum change the photophysiology and biochemistry of

142 diatom cells. Many other wavelength-dependent responses of cyanobacteria and eukaryotic 143 phytoplankton have been observed, especially in laboratory studies of cultures (Schreiber \& 144 Klughammer, 2013; Szabó et al., 2014a,b; Herbstová et al., 2015; Lawrenz \& Richardson, 2017; 145 Luimstra et al., 2018, 2020). Most field studies of wavelength-dependent acclimation focused on 146 relationships between accessory pigments, the shape of phytoplankton absorption spectra and the 147 underwater light climate (Hickman et al., 2009; Barlow et al., 2017), but few measured 148 photosynthetic parameters at different wavelengths. Some early studies used the carbon absorption 149 technique and determined $\alpha$ (in multispectral incubators), whose spectral correction through the 150 water column and/or between different water masses has been studied intensively (Lewis et al., 151 1985a,b; Kyewalyanga et al., 1992, 1997, 2002).

152 In the present study, we focused on wavelength-dependent parameters: $\alpha, \mathrm{ETR}_{\max }, \mathrm{E}_{\mathrm{k}}$, non153 photochemical quenching (NPQ)and light absorption capacity from 440-625 nm for different 154 natural phytoplankton communities sampled across environmental gradients of a coastal sea. A 155 specifically dedicated device - the multiple excitation wavelength chlorophyll fluorescence 156 analyzer (MULTI-COLOR-PAM) (Heinz Walz, Germany) - was used in its full capacity for the 157 first time in a field study. $\alpha, \mathrm{ETR}_{\max }, \mathrm{E}_{\mathrm{k}}$ and $\mathrm{E}_{\mathrm{op}}$ were determined from PE measurements at five 158 wavelengths as a function of the functional absorption cross section of PSII and NPQ for 19 159 locations sampled across the English Channel (EC). The EC is an epicontinental sea, particularly 160 suitable for studying photoacclimation strategies of microalgae. This ecosystem has many 161 environmental gradients between coastal and offshore water due to freshwater runoff and high 162 tidal currents (Brylinski et al., 1991). This area is dominated by diatoms and the Haptophyceae 163 Phaeocystis globosa during the spring bloom (Houliez et al., 2013a). Since i) the wavelength 164 dependence of light absorption capacity is related to the composition of PSII antenna pigment 165 composition, and ii) this composition changes in natural samples depending on phytoplankton community structure and specific photoacclimation processes in a given light climate, we tested

167 the hypothesis that phytoplankton $\mathrm{PET}_{\lambda}$ change in shape and level along environmental gradients 168 of light quantity and/or quality and phytoplankton community structure. The ecological 169 implications of wavelength dependence and plasticity of $\operatorname{PET}_{\lambda}$ parameters are then discussed in 170 the context of turbulent coastal ecosystems. To address these issues, an original analytical 
171 approach was developed that used three sequential statistical analyses: linear mixed-effects

172 models, partial triadic analysis and redundancy analysis.

173

174

175

176

177

178

179

180

181

182

183

184

185

186

187

188

189

190

191

192

193

194

195

196

197

198

\section{Materials \& Methods}

\subsection{Sampling area and strategy}

Data were collected during a combined sampling campaign of the JERICO-NEXT program and the 2018 ECOPEL cruise in the EC, from the Strait of Dover $\left(50^{\circ} 58.7^{\prime} \mathrm{N}, 1^{\circ} 36.64^{\prime} \mathrm{E}\right)$ to Brest $\left(48^{\circ} 20.59^{\prime} \mathrm{N}, 5^{\circ} 25.03\right.$ ' W) from 18 April to 2 May 2018 (Fig. 1). Water was sampled at 19 locations at a depth of $2 \mathrm{~m}$ from inshore to offshore water (using a 20 L Niskin bottle) at different times of day. This zigzag sampling strategy was chosen to consider hydrobiological gradients between coastal/offshore and east/west waters (Vantrepotte et al., 2007). To characterize the sampling hour, which can influence phytoplankton physiology, we calculated the number of hours that had elapsed since sunrise (i.e. time since sunrise (TSS) in h). The EC is an epicontinental macrotidal temperate system with strong hydrodynamics and substantial river inputs, which provide contrasting light climates that are useful for testing the wavelength-dependence hypothesis of photosynthesis in natural phytoplankton communities. The water bodies sampled were thus used to experiment with different light climates along environmental gradients and with changes in phytoplankton community structure.

\subsection{Controlling variables of photosynthesis}

Two types of variables that could control photosynthesis were analyzed as ex-situ experimental conditions under which the communities grew: i) abiotic variables and ii) biotic variables that describe the phytoplankton community structure.

\subsubsection{Abiotic variables: Hydrological and light measurements}

At each location, conductivity-temperature-depth (CTD) casts were conducted using a SBE25 CTD (Sea-Bird Scientific, USA). Water samples were filtered through a microfiber filter (Whatman GF/C or GF/F), and aliquots were then stored at $-20^{\circ} \mathrm{C}$ until further processing for dissolved inorganic nutrient concentrations. Concentrations of dissolved inorganic nitrogen (DIN i.e. $\left.\mathrm{NO}_{3}+\mathrm{NO}_{2}\right)$, phosphate $\left(\mathrm{PO}_{4}\right)$, and silicate $\left(\mathrm{Si}(\mathrm{OH})_{4}\right)$ were measured with an Integral Futura Autoanalyzer II (Alliance Instruments) according to the method of Aminot \& Kérouel (2004). 
199 Underwater spectra were measured with a spectroradiometer RAMSES ACC-VIS hyperspectral

200 radiometer (TriOS $\mathrm{GmbH}$, Germany) throughout the euphotic layer, but the present study 201 considered only spectroradiometer measurements from the surface to $2.5 \mathrm{~m}$ depth.

202 Spectroradiometer measurements were made in triplicate (on all spectrum) in the water column, 203 every $50 \mathrm{~cm}$, from the depth where the sensor was not uncovered by the waves. The photon fluence 204 rate was measured every $3 \mathrm{~nm}$ from 400-700 $\mathrm{nm}$. Three spectrum bands of interest for 205 photosynthesis (i.e. blue (B), green $(G)$ and red $(R))$ were obtained via quantum integration of 206 spectral bands (410-490, 480-580 and 600-700 nm, respectively). These spectral bands, expressed 207 in $\mu \mathrm{mol}$ quanta. $\mathrm{m}^{-2} \cdot \mathrm{s}^{-1}$, were chosen according to the study of Brunet et al., (2014). Intensity ratios 208 for three pairs of spectral bands were then calculated (i.e. R/B, G/B and G/R) and used as light209 quality ratios that depended on the overall chemical and biological characteristics of the waters 210 sampled (Jaubert et al., 2017). Finally, averages of these ratios were calculated for replicates of

211 the same depth and over a depth interval ranging between the first depth where it was possible to 212 perform a measurement and the depth of $2.5 \mathrm{~m}$. Depth profiles of photosynthetically active 213 radiation (PAR; 400-700 nm) were obtained using a PAR quantameter (LI-193 4pi from LICOR, 214 USA) connected to the CTD. Vertical diffuse attenuation coefficients for PAR were calculated as 215 follows:

$\left.216 \mathrm{~K}_{\mathrm{d}(\mathrm{PAR})}=\left[\ln \left(\mathrm{I}_{0}\right)-\ln \left(\mathrm{I}_{\mathrm{z}}\right)\right]\right) / \mathrm{Z}$

217 where $\mathrm{K}_{\mathrm{d}(\mathrm{PAR})}\left(\mathrm{m}^{-1}\right)$ is the downwelling diffuse attenuation coefficient of underwater light, and $\mathrm{I}_{0}$ 218 and $\mathrm{I}_{\mathrm{z}}$ are photon fluence rates $\left(\mu\right.$ molquanta $\left.\cdot \mathrm{m}^{-2} \cdot \mathrm{s}^{-1}\right)$ at the surface and depth $\mathrm{z}(\mathrm{m})$, respectively 219 (Kirk, 2011).

220 The depth of the euphotic layer $\left(Z_{\mathrm{eu}}\right.$ in $\mathrm{m}$ ) was then calculated (Eq. 2) for each location according 221 to Kirk (2011):

$222 \mathrm{Z}_{\mathrm{eu}}=4.6 / \mathrm{K}_{\mathrm{d}(\mathrm{PAR})}$

223 Vertically averaged light intensity $\left(E_{a v g}\right.$ in $\mu$ mol quanta $\left.\mathrm{m}^{-2} \mathrm{~s}^{-1}\right)$ in the mixed layer was calculated 224 (Eq. 3) according to Riley (1957):

225

$\mathrm{E}_{\mathrm{avg}}=\mathrm{I}_{0} \cdot\left[1-\mathrm{e}^{(-\mathrm{Kd}(\mathrm{PAR}) \times \text { Zumixl })}\right] /\left(\mathrm{K}_{\mathrm{d}(\mathrm{PAR})} \times \mathrm{Z}_{\mathrm{umixl}}\right)$ 
226 The depth of the upper mixed layer $\left(\mathrm{Z}_{\text {umixl }}\right.$ in $\left.\mathrm{m}\right)$ was defined from the CTD profiles using vertical 227 density gradients, caused by vertical temperature and salinity gradients, according to Van Leeuwen 228 et al., (2015). The water column was considered to be stratified if the difference in density between 229 the surface layer (0-1.5 m below the surface) and the bottom layer exceeded $0.086 \mathrm{~kg} \cdot \mathrm{m}^{-3}$ following 230 (Lowe et al., 2009). Thus, $Z_{\text {umixl }}$ is the depth of the water column without stratification. This 231 approach allowed us to consider that water columns in the EC, which are usually considered to be 232 mixed, may be occasionally stratified and thus influence phytoplankton physiology (Van Leeuwen 233 et al., 2015). Finally, we calculated the ratio $Z_{\text {eu }} / Z_{\text {umixl }}$ for each sampling location as a measure of 234 light availability in water, one of the key factors in phytoplankton photoacclimation (Jensen et al., 235 1994).

\subsubsection{Biotic variables: phytoplankton groups, biomass and sample preparation}

237

238

239

240

241

242

243

244

245

246

247

248

249

250

251

252

253

254

255

The FluoroProbe sensor (a multi-wavelength fluorometer, bbe Moldaenke GmbH, Germany) was used to estimate the composition of natural phytoplankton communities, as in several other studies (Houliez et al., 2013b,a, 2015). The FluoroProbe distinguished four groups of microalgae in vivo and instantaneously: diatoms plus dinoflagellates (i.e. "brown microalgae"), Haptophyceae (Phaeocystis globosa in the eastern EC (Houliez et al., 2012)), Cryptophyceae and Cyanophyceae. The biomass of each group was estimated as an equivalent concentration of Chla ( $\left.\mu \mathrm{g} . \mathrm{L}^{-1}\right)$. See Beutler et al., (2002) for more details about the FluoroProbe. For all photosynthetic parameters, phytoplankton samples were concentrated using a nylon phytoplankton net with a $20 \mu \mathrm{m}$ mesh and $30 \mathrm{~cm}$ diameter (Aquatic Research Instrument, USA), and then kept in the dark under temperaturecontrolled conditions close to the water sampled and in air-conditioned laboratory conditions before measuring photosynthesis. To measure photosynthesis accurately, the phytoplankton were concentrated to ensure that all samples had the same range of Chla concentration (ca. $100 \mu \mathrm{g} . \mathrm{L}^{-1}$ ). Phytoplankton biomass in each group was estimated with the FluoroProbe before and after concentrating it.

\subsection{Wavelength-dependent photosynthesis parameters and functional absorption cross section of PSII}

Wavelength-dependent $\mathrm{PET}_{\lambda}$ was studied using the MULTI-COLOR-PAM, which is particularly suitable for studying the $\mathrm{PET}_{\lambda}$ of phytoplankton (Schreiber et al., 2012). It provides pulsemodulated measuring light, continuous actinic light, single-turnover light pulses and multiple- 
256 turnover or saturation pulses with peak wavelengths at 440 (bright blue), 480 (light blue), 540

257 (green), 590 (amber) and $625 \mathrm{~nm}$ (red light). See Schreiber et al., (2012) for a full description.

258 Before measuring $\mathrm{PET}_{\lambda}$, samples were first dark-acclimated for $2.5 \mathrm{~h}$ (a compromise between the 259 analyses and sampling strategy), without far red exposure (that would have locked the device for 260 too long with respect to the many measurements required). The time of dark acclimation aims to 261 optimize the maximum quantum yield of PSII measurements and neutralize the recent light history 262 of cells (sampled in water columns of different depths and optical properties). It has been shown 263 that there is not an universal protocol and the time required can exceed the classically considered 264 time of 30 minutes and, in certain circumstances, durations of more than 2 hours are necessary 265 (From et al., 2014). First, each dark acclimated sample was homogenized within an optical quartz 266 cuvette with a magnetic stirrer then the light sensor US-SQS/WB Spherical Micro Quantum Sensor 267 (Heinz Walz, Germany) was placed into the center of the cuvette to measure the photon flux 268 density at each wavelength. This step provided the "PAR-list" file for each sample, which was 269 used for all later measurements of that sample. Water samples filtered at $0.2 \mu \mathrm{m}$ were used to 270 determine the zero offset (i.e. the background signal to subtract from the total fluorescence signal 271 at each wavelength). Next, a subsample of each dark acclimated sample was placed in a $2.5 \mathrm{~mL}$ 272 cuvette with a $1 \mathrm{~cm}$ path length to adjust the measuring light and gain settings to it in order to 273 obtain the same current fluorescence $(\mathrm{Ft})$ level of $0.5 \pm 0.05$ (relative units) for all wavelengths 274 and to get a good signal-noise ratio. This last step was used to compare fluorescence-rise kinetics 275 (Szabó et al., 2014a).

276 Then, fast kinetic photosynthesis was measured to determine the wavelength-dependent functional 277 absorption cross section of PSII (i.e. Sigma(II) $)_{\lambda}$ ) by measuring O- $\mathrm{I}_{1}$ fluorescence-rise kinetics 278 repeatedly, as described by Schreiber et al., (2012). Sigma(II) $)_{\lambda}$ was estimated using the pre279 programmed fast kinetic trigger file "Sigma1000.FTM", in the same way as Szabó et al., (2014a,b) 280 and Schreiber \& Klughammer (2015) did. In this phase of fast fluorescence, "O” was minimal 281 fluorescence yield corresponding to all PSII reaction centers open. The full closure of PSII reaction 282 centers $\tau$ (i.e. that of light-driven $\mathrm{Q}_{\mathrm{A}}$ reduction during the $\mathrm{O}-\mathrm{I}_{1}$ rise) was obtained during a standard $2831 \mathrm{~ms}$ long actinic illumination. Sigma(II) $\lambda$ was calculated according to Schreiber et al. (2012) as: 
285 where $\tau$ is the time constant (expressed here in seconds) of light driven $\mathrm{Q}_{\mathrm{A}}$ reduction determined 286 from the fast fluorescence kinetics measurements, L the Avogadro's constant $\left(6.022 .10^{23} \mathrm{~mol}^{-1}\right)$, 287 and PAR is the quantum flux density (that must be expressed here in mol quanta $\mathrm{m}^{-2} \mathrm{~s}^{-1}$ ) of the light 288 driving the $\mathrm{O}-\mathrm{I}_{1}$ fluorescence rise.

289 Sigma(II) $)_{\lambda}$ was calculated by the user software interface (PAM-Win-3, Heinz Walz) based on the 290 fitted value of the time constant $\tau$ obtained from three consecutive measurements separated by 10-s 291 dark intervals, according to (Klughammer \& Schreiber, 2015). Following this method, the estimate 292 of Sigma(II) $)_{\lambda}$ is independent of Chla concentration. Sigma(II) $\lambda$ was determined from six 293 subsamples to estimate the mean and variance of each natural community accurately 294 (Supplementary Material, Fig. S1).

295 Next, automated rapid light curves (RLC) of the $\mathrm{PET}_{\lambda}$ were determined in triplicate (i.e. three 296 independent samples) at each of the five wavelengths. For each RLC, samples were exposed to 14 297 actinic increasing light intensity levels, each $20 \mathrm{~s}$ long, as defined in the PAR-list file for each 298 wavelength and sample. Hereafter, "PAR" refers to the photon flux measured at each wavelength, 299 and the same wavelength was always used for the measuring light and actinic light. Saturation 300 pulse settings were defined at a width of $300 \mu \mathrm{s}$. The effective quantum yield of PSII (Y(II)) was 301 calculated at each step (Eq. 5). An initial step at $0 \mu \mathrm{mol}$ quanta.m $\mathrm{m}^{-2} \cdot \mathrm{s}^{-1}$ was used to determine $\mathrm{F}_{\mathrm{v}} / \mathrm{F}_{\mathrm{m}}$ 302 for samples acclimated to the dark for a long period (2.5 h) (Eq. 6). The relative electron transport 303 rate (r.ETR) was then determined using Y(II), the PAR intensity of the corresponding wavelength 304 (from the PAR-list file) and an arbitrary factor of 0.5 to indicate that PSI and PSII absorb light 305 equally (Eq. 7). The wavelength-dependent absolute electron transport rate of PSII (ETR(II) 306 reported in electrons (PSII s) ${ }^{-1}$ ) was then calculated from Sigma(II) $)_{\lambda}\left(\mathrm{nm}^{-2}\right)$, the Avogadro's 307 constant (L, 6.022.10 $\mathrm{mol}^{-1}$ ) and PAR(II) which is the rate of quantum absorption in PS II, in 308 units of quanta (PS II s) ${ }^{-1}$ according to Schreiber et al., (2012) at each of the five wavelengths (Eq. 3098 and 9).

$310 \mathrm{Y}(\mathrm{II})=\left(\mathrm{F}_{\mathrm{m}}^{\prime}-\mathrm{F}\right) / \mathrm{F}_{\mathrm{m}}^{\prime}$

$311 \quad \mathrm{~F}_{\mathrm{v}} / \mathrm{F}_{\mathrm{m}}=\left(\mathrm{F}_{\mathrm{m}}-\mathrm{F}_{0}\right) / \mathrm{F}_{\mathrm{m}}$

312 r.ETR $=\mathrm{Y}(\mathrm{II}) \times \mathrm{PAR} \times 0.5$ 
$313 \quad$ PAR $(\mathrm{II})=\operatorname{Sigma}(\mathrm{II}) \times \mathrm{L} \times \mathrm{PAR}$

$314 \quad \operatorname{ETR}(\mathrm{II})=\mathrm{PAR}(\mathrm{II}) \times\left[\mathrm{Y}(\mathrm{II}) / \mathrm{F}_{\mathrm{v}} / \mathrm{F}_{\mathrm{m}}\right]$

315 NPQ (Bilger \& Björkman, 1990) was calculated as the normalized Stern-Volmer quenching 316 coefficient (Eq. 10), according to Lavaud (2007):

$317 \mathrm{NPQ}=\mathrm{F}_{\mathrm{m}} / \mathrm{F}_{\mathrm{m}}^{\prime}-1$

318 All photosynthetic parameters were obtained in triplicate for the five wavelengths of MULTI319 COLOR-PAM for each sample.

320 The Eilers \& Peeters (1988) model was used to fit r.ETR vs. PAR and ETR(II) vs. PAR(II) curves

321 to estimate three photosynthetic parameters for each wavelength: light-use efficiency (i.e. $\alpha$, the 322 initial slope of the ETR vs. PAR curve), the maximum electron transport rate $\left.\left(\mathrm{ETR}_{\max }\right)\right)$ and the 323 optimum light parameter $\left(\mathrm{E}_{\mathrm{op}}\right)$ in relative (r) and absolute (II) units. The light saturation parameter $324\left(E_{k}\right)$ was also calculated in the two units as $E_{k}=E^{2} R_{\max } / \alpha$ (Talling, 1957). To estimate the degree 325 of photoacclimation of the phytoplankton communities, the $E_{k, 440} / E_{\text {avg }}$ ratio in $Z_{\text {umixl }}$ at sampling 326 was calculated for each location. The $\mathrm{E}_{\mathrm{k}}$ ratios (in relative and absolute units) of three pairs of 327 wavelengths $(625 / 440,540 / 440$ and $540 / 625 \mathrm{~nm})$ were calculated in the same way as the three 328 pairs of in situ spectral bands (i.e. R/B, G/B and G/R measured in a water layer of $2.5 \mathrm{~m}$ in surface 329 waters).

330 The Michaelis-Menten model was used to fit NPQ vs. PAR curves. A linear regression that forced 331 the intercept to zero was used when the kinetics of these curves differed from the Michaelis332 Menten model. Since two models were used, NPQ values were back-calculated using the calibrated 333 models at two irradiances (of PE curves) for each wavelength: low PAR (300 $\mu$ mol quantam ${ }^{-2} \cdot \mathrm{s}^{-1}$ ) 334 and, for saturating conditions, high PAR $\left(1200 \mu\right.$ mol.quanta $\left.\mathrm{m}^{-2} \cdot \mathrm{s}^{-1}\right)$, according to Szabó et al., 335 (2014a).

336 All PE curves were fitted using the "fitEP" function of the "phytotools" package of R software R 337 Core Team, (2020) specifically designed to fit phytoplankton photosynthesis curves using 338 simulated annealing (Silsbe \& Malkin, 2015). The curves for r.ETR vs. PAR, ETR(II) vs. PAR(II) 339 and NPQ vs. PAR were fitted for the three aggregated replicates, and all photosynthetic parameters 340 were obtained at each of the five wavelengths. 
341

342

343

344

345

346

347

348

349

350

351

352

353

354

355

356

357

358

359

360

361

362

363

364

365

366

367

368

369

370

\subsection{Statistical analysis}

All statistical analyses were performed with $\mathrm{R}$ version 3.6.0. For abiotic variables, the expectationmaximization with bootstrapping algorithm of Amelia II (Honaker et al., 2018) was used to determine missing values $(n=2)$ of light quality data. Principal component analysis (PCA) (Legendre \& Legendre, 2012) of abiotic and biotic variables was performed using the "PCA" function of the "FactoMineR" package (Husson et al., 2020) to determine the internal structure of locations that best explained the variance in each datasets. All data were centered and reduced before performing the PCA analysis.

Statistical analysis of photosynthetic parameters followed a three-step approach (Fig. 2). First, wavelength dependence of each parameter was analyzed using a linear mixed-effects model (LMEM). Mixed-effects models are commonly used to fit regressions to repeated (i.e. longitudinal) measures (over time and/or space) by separating the variance explained by the main effects from that explained by random sampling, while considering the wavelength dependence of individuals. The most parsimonious model was linear, and higher-degree polynomials were not significant. LMEMs (Bates et al., 2015) were thus used to analyze the population trend across wavelengths for each parameter. LMEMs were fitted using the "lmer" function of the "lmer4" package (Bates et al., 2019). Random effects, defined as differences of the locations from the population trend (intercepts and slopes), were used to study individual photoacclimation processes. Wavelengths from 440-625 $\mathrm{nm}$ were transposed to $0-185 \mathrm{~nm}$ to decrease uncertainty in the model intercept. Hypothesis tests were based on t-tests (for the intercept and slope of fixed effects) and likelihood-ratio tests based on the $\chi^{2}$ null hypothesis (for random effects)(Pinheiro \& Bates, 2000).

Second, each wavelength-dependent photosynthetic parameter was detrended by calculating individual differences from the population trend (from LMEMs) and then used in partial triadic analysis (PTA) (Thioulouse, 1987). PTA analyzes several two-way tables simultaneously (i.e. Ktables method). Five tables (one per wavelength) that contained 8 photosynthetic parameters (in columns) and 18 locations (in rows) were analyzed (location no. 8 was not considered on PTA analysis due to missing values at $590 \mathrm{~nm}$ ). Before analysis, all parameter values were centered and reduced based on their overall ranges from all tables. PTA identifies structures that are the same in all tables and assesses their stability among wavelengths. PTA was performed using the "pta" function of the "ade4" package (Dray et al., 2018), and related graphics were created with the 
371 “adegraphics” package (Siberchicot \& Julien-Laferrière, 2018). PTA was applied in three steps -

372 interstructure (an ordination), compromise and intrastructure analysis - which correspond to co-

373 variance, mean and variance structure analysis, respectively (Lavit et al., 1994; Mendes et al., 374 2010).

375 Third, redundancy analysis (RDA) of the same five wavelength-detrended tables as for the PTA 376 was performed to test for relationships between wavelength-dependent photosynthetic parameters 377 and explanatory abiotic and biotic variables. Data were centered and reduced before analysis. 378 Explanatory variables were selected for the model using an automatic stepwise model (the 379 "ordiR2step" function of the "vegan" package (Oksanen et al., 2019)) that performs forward 380 selection based solely on the adjusted $\mathrm{R}^{2}$ and $\mathrm{p}$-value (199 permutations). At each step, the variable 381 with the highest additional fit was added to the model.

382

383

384

385

386

387

388

389

390

391

392

393

394

395

396

397

398

399

400

\section{Results}

\subsection{Abiotic and biotic variables}

The experimental conditions determined by the abiotic PCA showed contrasting results. For abiotic variables, the first two axes of the PCA explained $66.1 \%$ of total inertia $(49.5 \%$ and $16.6 \%$, respectively) (Fig. 3A). The first axis distinguished samples based on their light-quality ratios $(\mathrm{R} / \mathrm{B}, \mathrm{G} / \mathrm{B}$ and $\mathrm{G} / \mathrm{R})$, vertical light attenuation coefficient $\left(\mathrm{K}_{\mathrm{d}(\mathrm{PAR})}\right), \mathrm{Z}_{\mathrm{eu}}, \mathrm{Z}_{\mathrm{umixl}}$, salinity and $\mathrm{PO}_{4}$ concentration (Fig. 3A). The second axis distinguished samples based on their DIN concentration, temperature, $\mathrm{Si}(\mathrm{OH})_{4}$ concentration and light intensity at a depth of $2 \mathrm{~m}\left(\mathrm{PAR}_{2 \mathrm{~m}}\right)($ Fig. 3A). Three groups of samples were distinguished. Group 1 (samples 12, 18, 22, 31, 33, 38 and 49) had intermediate-to-high DIN ( $>2 \mu \mathrm{mol} . \mathrm{L}^{-1}$, up to $30 \mu \mathrm{mol} . \mathrm{L}^{-1}$ near Seine Bay) and temperatures (9.5$12.0^{\circ} \mathrm{C}$ ), low-to-intermediate salinity ( $\left.<34 \mathrm{PSU}\right)$ and $\operatorname{PAR}_{2 \mathrm{~m}}\left(20-182 \mu \mathrm{mol}\right.$ quantam $\left.{ }^{-2} \cdot \mathrm{s}^{-1}\right)$, the highest $\mathrm{R} / \mathrm{B}$ and $\mathrm{G} / \mathrm{B}$ ratios (mean of 0.9 and 1.9 , respectively), the highest $\mathrm{K}_{\mathrm{d}(\mathrm{PAR})}\left(0.2-0.5 \mathrm{~m}^{-1}\right)$, the shallowest $Z_{\text {eu }}(9-23 \mathrm{~m})$ and $Z_{\text {umixl }}(6.5-21.0 \mathrm{~m})$, and the lowest $\mathrm{G} / \mathrm{R}$ ratio $( \pm 2)$. On the opposite side of the factorial map, group 2 (samples 28, 37, 43, 45, 46 and 53) had the highest $\mathrm{PO}_{4}$ and $\mathrm{Si}(\mathrm{OH})_{4}$ concentrations ( $>1$ and 0.5-2.0 $\mu \mathrm{mol} . \mathrm{L}^{-1}$, respectively) and salinity (mean of $\left.35 \mathrm{PSU}\right)$, the lowest $\mathrm{R} / \mathrm{B}$ and $\mathrm{G} / \mathrm{B}$ ratios, the highest $\mathrm{G} / \mathrm{R}$ ratios, the lowest $\mathrm{K}_{\mathrm{d}(\mathrm{PAR})}\left(0.07-0.17 \mathrm{~m}^{-1}\right)$, and the deepest $Z_{\text {eu }}(26-63 \mathrm{~m})$ and $Z_{\text {umixl }}(17-78 \mathrm{~m}$ ). Group 3 (samples 8, 10, 13, 25, 35 and 41) had intermediate salinity (33.5-35.0 PSU), the lowest temperatures $\left(<10^{\circ} \mathrm{C}\right)$ and DIN concentration, intermediate light-quality ratios, and the highest $\mathrm{PAR}_{2 \mathrm{~m}}$, but with high variability $(116-930 \mu \mathrm{mol}$

Peer] reviewing PDF | (2020:12:56632:2:0:NEW 22 Jul 2021) 
401 quanta $\left.\mathrm{m}^{-2} \cdot \mathrm{s}^{-1}\right)$. Thus, PAR in the abiotic PCA did not distinguish sampling locations well, nor did 402 TSS. Samples had TSS less than $2 \mathrm{~h}$ (samples 10, 18, 28, 33, 38, 46, 49 and 53), greater than $10 \mathrm{~h}$ 403 (samples 22, 31, 37 and 45) or values between the two (samples 8, 10, 13, 25, 35, 41 and 43). 404 Group 1 had locations near the coast, while group 2 had locations offshore. Detailed information 405 on abiotic variables is shown in the Supplementary Material, Figs. S2 and S3.

406 The biotic PCA based on FluoroProbe measurements of the biomass of main phytoplankton groups 407 (Fig. 3B) distinguished samples mainly based on the biomass of P. globosa; however, the range 408 of variation was low $( \pm 25 \%)$. The first axis distinguished $P$. globosa from brown microalgae and 409 cryptophytes, while the second axis distinguished Cyanobacteria. The results indicate that $P$. 410 globosa co-dominated with diatoms at several locations, and P. globosa dominated only samples 411 from locations 10, 12, 13, 18 and 22. Samples from three locations (41, 43 and 46) contained the 412 most cyanobacteria. Details of phytoplankton groups by location are shown in the Supplementary 413 Material, Fig. S4.

$414 \quad$ 3.2. Wavelength-dependent photosynthetic parameters from linear mixed-effects $415 \quad$ models

416 Fixed effects of the LMEMs represented the population trend of each photosynthetic parameter 417 once the spatial nature of the data sampling was considered (Fig. 4). All intercepts were significant, 418 indicating that all parameters differed from zero in the bright blue wavelength (440 nm) (Table 2). 419 Wavelength dependence led to a significant slope of the fixed effect for all parameters except $420 \mathrm{ETR}_{\max }$ (II) and $\mathrm{E}_{\mathrm{op}}$ (II), but the sign of each slope varied among parameters. While the slope of $421 \quad \mathrm{~F}_{\mathrm{v}} / \mathrm{F}_{\mathrm{m}}$ was significant, its small decrease across wavelengths was considered null for simplicity 422 (Fig 4A).

423 Sigma $(\mathrm{II})_{\lambda}$ is a key parameter since it connects relative and absolute parameters such as $\alpha, \mathrm{ETR}_{\max }$, $424 \mathrm{E}_{\mathrm{k}}$ and $\mathrm{E}_{\mathrm{op}}$. Population trend of Sigma(II) $)_{\lambda}$ decreased by a factor of 3 across wavelengths (from 6 425 to $2 \mathrm{~nm}^{2}$, Fig. 4B). Conversely, r.ETR ${ }_{\max }$ trend increased by a factor of 3 (from 50 to 150, Fig. 426 5C), which may have counteracted the decrease in Sigma(II $)_{\lambda}$ trend and led to the null slope of 427 ETR $_{\max }$ (II) trend (Fig. 4D). Trends of r. $\alpha$ and $\alpha(\mathrm{II})$ increased as wavelength increased (Figs. 4E 428 and F), and sharply for the latter, which increased by a factor of 2 . Since $E_{k}$ is the ratio of $E_{\text {TRax }}$ 429 to $\alpha$, r. $E_{k}$ increased and $E_{k}(I I)$ decreased as wavelength increased (Figs. 4G and H). Since $E_{o p}$ 
430 values were highly scattered, they were not considered in later analyses (Figs. 4I and J). The 431 decreasing trend in NPQs was higher at 1200 than at $300 \mu \mathrm{mol}$ quanta.m $\mathrm{m}^{-2} \mathrm{~s}^{-1}$ (Figs. 4K and L).

432 Since NPQ was estimated at low and high PAR from the PE curves, it is interesting to note that 433 the NPQ trends were opposite to those in r.ETR $\max$ and r. $\alpha$ (Figs. 4C and E respectively), meaning 434 that NPQs could have more influence on the values of these parameters under the blue wavelengths $435\left(\mathrm{NPQ}_{440}\right.$ and $\mathrm{NPQ}_{480}$ ranged from 1-2) than under the light red wavelength $\left(\mathrm{NPQ}_{625}\right.$ reached 0.2 at $436 \mathrm{PAR}=300 \mu$ molquanta. $\left.\mathrm{m}^{-2} \cdot \mathrm{s}^{-1}\right)$. The increasing trend in $\alpha(\mathrm{II})$ across spectrum could thus 437 correspond to a strong decrease in $\alpha($ II) under the blue wavelengths and not to an optimization 438 under the light red wavelength.

439 For the random effects, intercepts of all parameters were highly significant, but their slopes were 440 not, except for $\mathrm{ETR}_{\max }$ and $\mathrm{E}_{\mathrm{k}}$ in relative (r) and absolute (II) values (Table 2). Thus, parameter 441 values differed among samples but, except for $\mathrm{ETR}_{\max }$ and $\mathrm{E}_{\mathrm{k}}$, had the same trend across 442 wavelengths. This resulted in spatial differences in the spectral balance between bright blue and 443 light red wavelengths for $\mathrm{ETR}_{\max }$ and the photoacclimation parameters $\mathrm{E}_{\mathrm{k}}$ (in relative and absolute 444 units for the both).

445 When examining detrended values of absolute parameters among locations (Fig. 5), those of 446 ETR $_{\max }$ (II) and $\mathrm{E}_{\mathrm{k}}$ (II) tended to differ among the five wavelengths by sampling location (Figs 5C 447 and E), unlike those of the other parameters, which were generally more similar among the five 448 wavelengths by sampling location. This was especially true for detrended values of $\alpha$ (II) and $449 \mathrm{~F}_{\mathrm{v}} / \mathrm{F}_{\mathrm{m}}$, which differed little and almost not at all, respectively, among the five wavelengths by 450 location (Figs 5A and B). Because values of Sigma(II) $\lambda$ under the light red wavelength were not 451 always the lowest across wavelengths (i.e. a slightly non-linear distribution) (Fig. 4B), its 452 detrended values under the light red wavelength were higher than the population trend (Fig. 5A). 453 According to the statistical analyses, however, a linear model fit best to Sigma(II) $\lambda$ values.

\section{$454 \quad$ 3.3. Sample wavelength dependence of samples from the PTA}

455 The first two axes of the PTA interstructure explained 85.38\% of total inertia (Supplementary 456 Material, Fig. S5), and the five wavelength tables had similar weights (0.38-0.47; Table 3) and a 457 significant representation ( $\cos ^{2}$ close to 1; Table 3). The PTA was thus adequate overall and 458 highlighted similarities among the wavelengths. All five wavelengths were positively correlated 
459 and positively projected on the first axis (ca. 71.24\% of the total inertia; Supplementary Material, 460 Fig. S5). The second axis separated the bright blue and green wavelengths from the amber and

461 light red wavelengths. The amber wavelength differed the most from the others and had the same 462 correlation with the first and second axes.

463 When projecting the wavelength-dependent photosynthetic parameters on the compromise 464 coordinates it explained $66.49 \%$ of total inertia (Table 4, Fig. 6A), the relative positions of 465 polygons indicated that PTA results generally met our expectations: opposition between the group 466 of $F_{v} / F_{m}, \alpha(I I)$ and $E_{T R} R_{\max }(\mathrm{II})$ vs. the group of Sigma(II) $\lambda$ and $\mathrm{NPQ}_{300-1200}$, with parameters related 467 to photoacclimation $\left(\mathrm{E}_{\mathrm{k}}\right.$ and $\mathrm{E}_{\mathrm{op}}$ ) between these two groups. We observed the well-known 468 relationships between variables related to energy flows $\left(\mathrm{F}_{\mathrm{v}} / \mathrm{F}_{\mathrm{m}}\right.$ and $\left.\mathrm{NPQ} \mathrm{Q}_{300-1200}\right)$, related to 469 Sigma(II) $)_{\lambda}$, and the major parameters that control PE relations in absolute units $-\alpha($ II) and $470 \mathrm{ETR}_{\max }(\mathrm{II})$ - which had a positive overall correlation.

471 The intrastructure of the PTA showed differences between photosynthetic parameter patterns 472 among the five wavelengths (Figs. 6A to E). Patterns for the main parameters, such as ETR $\max _{\text {(II), }}$ $473 \alpha(\mathrm{II})$, Sigma(II) $)_{\lambda}$ and $\mathrm{NPQ}_{300-1200}$, changed from the bright blue wavelength $(440 \mathrm{~nm})$ to light red 474 wavelength $(625 \mathrm{~nm})$. The most evident change was the rotation of $\alpha($ II) and NPQ300-1200 475 respected to the spectral pattern of Sigma(II) $)_{\lambda}$. At blue wavelengths Sigma(II) $)_{\lambda}$ and NPQ300-1200 476 were inversely correlated to $\alpha$ (II) (Fig. 6A) but at amber and light red wavelengths there were any 477 correlation (Figs. 6D and E). Sigma(II) $\lambda$ was incorrectly represented in the main plane at $625 \mathrm{~nm}$ 478 (Fig. 6E). The PTA intrastructure analysis also showed patterns for the locations among the five 479 wavelengths (Fig. 7). Wavelength dependence differed greatly among locations: polygons were 480 largest for locations 33, 35, 43, 37 and 45, and smallest for locations 13, 18, 31, 46 and 53 (Fig. 481 7). In addition, the blue wavelengths (440 and $480 \mathrm{~nm}$ ) displayed a general circular change among 482 locations, moving from the right of the polygon for location 53 to the left for location 45 (Fig. 7).

483 484 485 486 487
3.4. Explanatory variables of wavelength dependence from RDA and linear regression

The RDA results showed that abiotic variables related to light emerged first as explanatory variables (Table 5). Euphotic depth $\left(Z_{\text {eu }}\right)$ was selected the most often, for three of the five wavelengths (Table 5), from 440-540 nm. TSS, which represents the recent light history of cells, 
488 was selected twice, for the light blue wavelength $(480 \mathrm{~nm})$ and the amber wavelength $(590 \mathrm{~nm})$.

489 The G/R light ratios were selected for the amber wavelength (590 nm). DIN concentration was the 490 only non-light parameter selected, for the light blue wavelength. No variables were selected for

491 the light red wavelength $(625 \mathrm{~nm})$, and $\mathrm{PAR}_{2 \mathrm{~m}}$ did not seem to influence the parameters.

492 To further explore the influence of $Z_{\mathrm{eu}}$ and the difference in control of photosynthetic parameters

493 under bright blue and light red wavelengths, we sought specific connections between the 494 photoacclimation parameter $\mathrm{E}_{\mathrm{k}}$ and $\mathrm{Z}_{\mathrm{eu}}$ (in ratios with $\mathrm{E}_{\mathrm{avg}}$ and $\mathrm{Z}_{\mathrm{umixl}}$, respectively), and between 495 the ratio of $\mathrm{E}_{\mathrm{k}}$ (in relative and absolute units) measured at 625 and $440 \mathrm{~nm}$ and the corresponding $496 \mathrm{R} / \mathrm{B}$ light ratio $\left(\mathrm{E}_{625 / 440}\right)$ in water masses. Two significant linear trends were found between the $497 \mathrm{E}_{\mathrm{k}, 440} / \mathrm{E}_{\mathrm{avg}}$ ratio (in relative and absolute units) and the $\mathrm{Z}_{\mathrm{eu}} / \mathrm{Z}_{\mathrm{umixl}}$ ratio for stratified water columns 498 (Fig. 8A for graphs and correlation coefficients). Correlations were non-significant for non499 stratified water columns for r. $_{\mathrm{k}, 440}$ and $\mathrm{E}_{\mathrm{k}}(\mathrm{II})_{440}$, as well as under the other wavelengths. 500 Considering all sampling locations revealed other significant correlations between the absolute 501 ratio $\mathrm{E}_{\mathrm{k}}(\mathrm{II})_{625 / 440}$ and (1) the red/ blue light ratios in surface waters $\mathrm{E}_{625 / 440}$ (see Fig. 8B for 502 correlation coefficients) and (2) the TSS factor ( $=-0.65, n=19, p<0.05$, Supplementary Material, 503 Fig. S6).

\section{Discussion}

506 Our results provide new insights into the wavelength dependence of photosynthetic parameters and PSII functional absorption cross section of coastal water phytoplankton communities. To date, the literature has focused on one or two species under a few growth conditions in the laboratory (Schreiber \& Klughammer, 2013; Brunet et al., 2014; Szabó et al., 2014a; Luimstra et al., 2018) or older in situ studies that focused on the wavelength dependence of $\alpha$ in the water column (Lewis et al., 1985b; Lewis et al., 1988; Kyewalyanga et al., 1992). Studying the present dataset including

512 all photosynthetic parameters was complex due to environmental gradients and changes in 513 community structure but made possible by the use of three powerful statistical methods. The 514 wavelength dependence of photosynthetic parameters that was characterized at the population

515 level and the sample level, will be discussed first in relation to the theories on photosynthesis and 516 photoacclimation, and then from an ecological point of view. 


\subsection{Physiological meaning of wavelength dependence of photosynthetic}

518

519

520

521

522

523

524

525

526

527

528

529

530

531

532

533

534

535

536

537

538

539

540

541

542

543

544

545

546 parameters

\subsubsection{Light absorption capacity}

Since light absorption was measured according to the method of Schreiber et al., (2012), Sigma(II) $)_{\lambda}$ can be considered an intrinsic property of the PSII units for each sample. Thus, the recent light history at sampling did not change the light absorption capacity of the 19 samples studied. Cell light absorption was thus a function of only pigment composition of photosynthetic units (Schreiber et al., 2012), even though the packaging effect may slightly skew the relation between Sigma(II) $\lambda$ measurements and pigment concentration (Gorbunov et al., 2020). Since the slopes of the fixed (population level) and random (individual level) effects were significant and nonsignificant, respectively, all of the phytoplankton communities absorbed more light in the blue spectral range and with the same wavelength dependence, regardless of the sample.

Given the sampling area, we expected the decreasing population trend in Sigma(II) $)_{\lambda}$ across wavelengths. This is a typical result for cell communities dominated by brown microalgae such as diatoms with Chla as the main light-absorbing pigment (Kuczynska et al., 2015). The small increase under the light red wavelength $(625 \mathrm{~nm})$ is also consistent with this result (since Chla also absorbs red light), and with other Sigma(II $)_{\lambda}$ measurements for diatoms using the same method (Goessling et al., 2018b). This is consistent with our group-based community-structure measurements, which show that the diatom-dinoflagellate and haptophyte groups dominated all 19 samples. Consequently, the phytoplankton communities may not have been composed of species with completely opposite strategies for light absorption, as is common in experimental and theoretical modeling studies (Luimstra et al., 2019; Burson et al., 2019). Thus, the following discussion focuses on the plasticity of typical brown microalgae communities to the wavelength dependence of light climates in coastal water depending on their physiological state.

Conversely, the absence of significant individual wavelength dependence for Sigma(II $)_{\lambda}$ among the 19 samples was unexpected; however, the light absorption capacity differed among samples regardless of the wavelength. Signature changes over the spectrum were expected because the spectral quality of light is crucial for microalgae to achieve optimal photoacclimation in the face of variable light quality and intensity during growth (Valle et al., 2014). Light quality can influence gene expression that adjusts pigment and protein compositions of specific antenna complexes (e.g. 
547 fucoxanthin-chlorophyll a/c-binding antenna pigment-protein complex of diatoms called FCP),

548 which changes spectral absorption by cells. Conversely, light quantity can influence only pigment 549 concentrations (Valle et al., 2014). In the present study, the changes in light quality may have been

550 too small to induce significant changes in spectral absorption capacity among the 19 samples due

551 to hydrodynamic conditions and the daylight cycle, which agrees with the results of Gorbunov et

552 al., (2020). Cells could have managed variations in incident light quality via their photosynthetic

553 apparatus without having to change their pigment composition. However, changes in light intensity

554 were sufficient to produce significantly different spectral absorption capacities among samples.

555 The relatively high light absorption capacity of cells under the green wavelength (540 $\mathrm{nm})$ agrees 556 with results of Goessling et al., (2018b) for a planktonic diatom and for microphytobenthic

557 diatoms (Goessling et al., 2018a), but does not agree with those of a brown-gold microalga

558 Nannocloropsis oculata (Eustigmqtophyceae) (Szabó et al., 2014a) using the same method as in

559 the present study. This could be because some or all cells in the communities of the present study

560 were acclimated to green wavelengths in the water column. The green light ratios (G/B and G/R)

561 measured always exceeded 1, indicating that green wavelengths dominated in all sampling

562 conditions. It is well known that green light dominates coastal water during the algal blooms

563 because the high chlorophyll concentration absorbs blue wavelengths (Kirk, 2011). This

564 absorption capacity in the green spectral band could be due to an increase in the "green" absorption

565 capacity of fucoxanthin, which absorbs more energy from 390-580 nm due to the basic structural

566 and functional properties of fucoxanthin and its location in the light-harvesting complex proteins

567 of the antenna (Premvardhan et al., 2008; Kuczynska et al., 2015). Burson et al., (2018) also

568 showed continuous light absorption spectra, with better green light absorption capacity for a 569 fucoxanthin diatom than for green and blue-green phytoplankton, in agreement with Valle et al., 570 (2014).

\section{$571 \quad$ 4.1.2. General physiological state}

572 The population trend across wavelengths and $\mathrm{F}_{\mathrm{v}} / \mathrm{F}_{\mathrm{m}}$ values indicate that cells were in a good 573 physiological state, considering the community composition based on diatoms and Phaeocystis 574 globosa, regardless of the wavelength and thus were not under high nutrient stress. The population

575 trend of $\mathrm{F}_{\mathrm{v}} / \mathrm{F}_{\mathrm{m}}$ was centered on 0.6 , and $\mathrm{F}_{\mathrm{v}} / \mathrm{F}_{\mathrm{m}}$ values were never less than 0.4. Generally, the 576 theoretical maximum of $\mathrm{F}_{\mathrm{v}} / \mathrm{F}_{\mathrm{m}}$ is 0.7 (in a dark-adapted state, as in this study), and its critical value 
577 is 0.3 (Painter et al., 2010) for communities dominated by brown microalgae (diatoms and

578 dinoflagellates). We will not discuss here the complex links between nutrients and photosynthetic

579 parameters, this is not our topic and this was done specifically in other works for the same

580 ecosystem (Napoléon, et al. 2013b). In addition, the good nutrient status of water is confirmed by

581 comparing nutrient concentration measurements in the present study to the seasonal nutrient cycle

582 established for the EC (Gentilhomme \& Lizon, 1998). Using a similar measurement method, Szabó

583 et al., (2014b) observed similar values of $\mathrm{F}_{\mathrm{v}} / \mathrm{F}_{\mathrm{m}}$ across wavelengths (which approached 0.7 ) for

584 cultures in nutrient-replete conditions. Gorai et al., (2014) observed spectral independence of $\mathrm{F}_{\mathrm{v}} / \mathrm{F}_{\mathrm{m}}$

585 when comparing physiological properties of a culture under blue and white lights.

586

\subsubsection{Spectral trends and photoacclimation processes}

587 In this context of samples with the same wavelength dependence of light absorption and good 588 physiological state, wavelength photoacclimation can be investigated through trends in $589 \mathrm{ETR}_{\max }(\mathrm{II}), \alpha(\mathrm{II}), \mathrm{NPQ}$ and $\mathrm{E}_{\mathrm{k}}$. Although r.ETR $\max$ and $\mathrm{r} . \alpha$ had a significant trend across 590 wavelengths, they do not provide enough information to understand the spectral dependence of

591 photosynthesis in detail, which is a function of light absorption, given here by Sigma(II) $\lambda$

592 (Schreiber et al., 2012). These relative parameters are useful only to compare and better understand 593 the influence of Sigma(II) $\lambda$ on spectral photosynthetic processes in absolute units. Both parameters 594 had a positive slope across wavelengths, indicating that r.ETR $\mathrm{max}_{\max }$ and r. $\alpha$ spectra were the inverse 595 of the Sigma(II) $)_{\lambda}$ spectrum; conversely, in absolute units, the slope of $\mathrm{ETR}_{\max }$ (II) disappeared, 596 while the positive slope of $\alpha($ II) was maintained. These results were unexpected since water was 597 sampled at different times of the day, and cells were kept in the dark for $2.5 \mathrm{~h}$ before being 598 analyzed. An explanation could be that cells in the samples were in a wavelength-dependent 599 photoprotective state due to the underwater light climate.

600 We expected the trend of $\operatorname{ETR}_{\max }$ (II) to decrease over the spectrum because the cells grew in a 601 natural environment in which blue and green light dominated, since red light is quickly absorbed 602 in the water column (the R/B ratios were usually less than 1). Several studies involving 603 phytoplankton and microphytobenthos observed increasing values of $\mathrm{ETR}_{\max }$ (II) in the blue 604 wavelength (Mercado et al., 2004; Szabó et al., 2014a; Goessling et al., 2016, 2018a) related to 605 changing light conditions. Opposite results have also been found. Schreiber et al., (2012) indicated 606 that photoinhibition could explain the decrease in $\mathrm{ETR}_{\max }$ (II) under blue light, that the time needed 
607 to recover the starting values is much longer under bright blue than light red wavelengths, and that 608 the recovery under blue light remains only partial after several hours. Correa-Reyes et al., (2001) 609 observed that growth rates of eight microphytobenthic species decreased more under blue light 610 than light of other colors. In the present study, given the higher light absorption in blue (440 and $611480 \mathrm{~nm})$ than light red wavelengths $(625 \mathrm{~nm})$, and since the high energy of blue wavelengths can

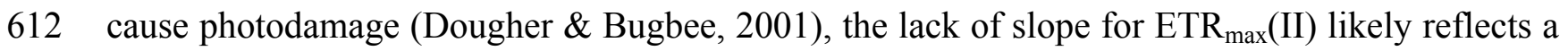
613 photoinhibition or photoprotective state of the communities towards blue wavelengths, which 614 initially decreased r.ETR ${ }_{\max }$ values under blue light. For $\operatorname{ETR}_{\max }(\mathrm{II})$, significant wavelength 615 dependence among the 19 samples is superimposed on the non-significant population trend. Thus, 616 some samples had different degrees of photoinhibition/photoprotection under blue light 617 independent of other light colors. We can thus speculate about wavelength dependence of 618 photoinhibition/photoprotection mechanisms.

619 We expected high r. $\alpha$ and especially $\alpha($ II) under blue wavelengths and thus a decreasing trend 620 from $440-590 \mathrm{~nm}$, with a small increase at $625 \mathrm{~nm}$. The variation in $\alpha$ as a function of light quality 621 is the best known photosynthetic parameter because it was closely studied from the mid-1980s to 622 the early 2000s by carbon-14 incorporation, for calculations of primary production rate (Lewis et 623 al., 1985 a, b, 1988; Kyewalyanga et al., 1992, 1997, 2002). At worst, a null slope of $\alpha($ II) over 624 the spectrum, like for $\operatorname{ETR}_{\max }(\mathrm{II})$, was expected, but the consistently lower values in the blue 625 wavelengths were unexpected given the Sigma(II $)_{\lambda}$ variations observed and previous studies of 626 natural communities (Lewis et al., 1985a) or brown microalgae cultures of a red tide dinoflagellate 627 (Schofield et al., 1996 talking about Pyrrophyta). This result does not reflect an improvement in 628 red light-use efficiency, since brown microalgae requires $24-48 \mathrm{~h}$ to photoacclimate to changes in 629 red light (Valle et al., 2014 about the marine diatom Phaeodactylum tricornutum), which is 630 consistent with properties of the underwater light climate. Unlike red light, high-intensity blue 631 light can cause rapid changes in cells, such as energy allocation between photosynthetic and 632 photoprotective pathways in coastal species (Lavaud, 2007; Brunet \& Lavaud, 2010). As many 633 experimental studies show, the cycle of xanthophyll (a photoprotective pigment) and NPQ are 634 fundamental photoprotective processes that are activated within seconds to minutes to dissipate 635 excess absorbed light energy (Dimier et al., 2009). Energy dissipation by carotenoids can reduce 636 photosynthetic rates under blue light, which increases NPQ (Brunet et al., 2014). Many other 
637 studies have used NPQ to measure the overall photoprotective capacity of the photosynthetic 638 apparatus (e.g. Dimier et al., 2007; Lavaud, 2007). The xanthophyll cycle photoprotective 639 mechanism has been observed in the coastal sea of the EC for the same locations the phytoplankton 640 communities in this study have been collected (Brunet et al., 1993; Brunet \& Lizon, 2003) and in 641 permanently well-mixed ecosystems (Alderkamp et al., 2011). Therefore, like for $\operatorname{ETR}_{\max }(\mathrm{II})$, the 642 decrease in the trend of $\alpha$ (II) observed over the spectrum could be due to photoinhibition and, 643 more likely, photoprotection. Photoinhibition of $\alpha$ has been experimentally verified (Björkman \& 644 Demmig, 1987; Baker \& Bowyer, 1994):

645 The hypothesis of a photoprotective influence on $\alpha$ (in relative and absolute units) requires that 646 photoprotection occur early and at low light intensities. Consistent with this hypothesis, NPQ 647 population trends were significant and values were always higher under blue than red light at low 648 intensities. These results are confirmed by those of Goessling et al., (2018a) for suspensions of 649 phytobenthic diatoms and those of Tamburic et al., (2014) for a brown-gold 650 microalgaeNannocloropsis occulata (Eustigmqtophyceae). In the present study, NPQ was ca. 1 651 and 2 under low- and high-intensity blue light, respectively. According to Lefebvre et al., (2011), 652 NPQ usually exceeds 1 for cells that face the sun and are not well adapted to high-intensity light.

653 Thus, since communities in the present study had adequate photoprotective capacity against blue 654 light, maximum quantum efficiency $\mathrm{F}_{\mathrm{v}} / \mathrm{F}_{\mathrm{m}}$ was always high regardless of the wavelength, while 655 effective quantum efficiency, which influences $\alpha$ and $E T_{\max }$, decreased early under blue light 656 (and probably green light). This created slightly different spectral signatures for $\alpha($ II), which is 657 determined under low light intensity, among the samples depending on the in situ light intensity, 658 which thus likely decreased wavelength effects. Conversely, $\operatorname{ETR}_{\max }$ (II) is determined under 659 higher light intensity, in which individual spectral effects were efficient. To support this 660 hypothesis, blue light is expected to be less prone to cause photoinhibition such as photodamage 661 than red light (Brunet et al., 2014), and cells have greater PSII repair capacity under blue light than 662 red light, since photoprotection and PSII repair are induced by protein-encoding genes under blue 663 light, but are lacking under red light (Valle et al., 2014).

664 In this context, $\mathrm{E}_{\mathrm{k}}$ varied across wavelengths due to relative variations in $\mathrm{ETR}_{\max }$ and $\alpha$, since $665 \mathrm{E}_{\mathrm{k}}=\mathrm{ETR}_{\max } / \alpha$. Values of $\mathrm{r} . \mathrm{E}_{\mathrm{k}}$ were indeed lower in the blue wavelengths, while those of $\mathrm{E}_{\mathrm{k}}$ (II) 
666 were higher. These results are fairly consistent with our hypothesis for communities in the 667 photoprotective state rather than the photoinhibition state, as are the high $F_{v} / F_{m}$ values under blue 668 wavelengths. This is supported by the two significant correlations observed between the $\mathrm{E}_{\mathrm{k}, 400} / \mathrm{E}_{\mathrm{avg}}$ 669 ratio (in relative and absolute units) and the $Z_{\text {eu }} / Z_{u m i x l}$ ratio, indicating that the communities were 670 in good agreement with the high light availability in the mixed layer (Jensen et al., 1994; Wang et 671 al., 2011). This is particularly true for the $\mathrm{rE}_{\mathrm{k}, 400} / \mathrm{E}_{\mathrm{avg}}$ ratio, which tended towards the reference 672 value of 1 at four locations that had stratified water columns. Values close to 1 indicate 673 optimization of absorbed light by photosynthetic metabolism (Anning et al., 2000, 2001). To our 674 knowledge, these two correlations are new results for an ecosystem known for its high 675 hydrodynamic regime. Most studies in dynamic coastal ecosystems observed cells in a 676 photoacclimation state and r. $\mathrm{E}_{\mathrm{k}}$ values less than or greater than 1 (Claquin et al., 2010; Houliez et 677 al., 2013a). One exception is Jouenne et al., (2005) in the Baie des Veys (French coast), who used 678 carbon-14 measurements rather than active fluorescence measurements. The photoprotective state, 679 based on NPQ under in situ irradiance, includes well-known processes that can operate 680 continuously to protect microalgae from potential photoinhibition and, after photodamage, 681 correspond well to photoacclimation processes (Alderkamp et al., 2013). The physiological 682 plasticity of phytoplankton in limiting photodamage usually explains much of the diurnal variation 683 in photosynthetic processes (Schuback et al., 2016). These include many processes of the 684 photosynthetic apparatus that influence $\mathrm{r}_{\mathrm{k}} \mathrm{E}_{\mathrm{k}}$ and $\mathrm{E}_{\mathrm{k}}(\mathrm{II})$ to match the in situ light intensity (Dubinsky $685 \&$ Stambler, 2009; Schofield et al., 2013).

686 The advantage of measuring photosynthesis at several wavelengths using the functional light 687 absorption capacity of natural phytoplankton is revealed by the differing trends of the 688 photosynthetic parameters observed over the spectrum. Comparing the spectral trends and 689 estimating the absolute photosynthetic parameter were necessary to identify the photoacclimation 690 state of the 19 samples.

\subsection{Ecological meaning of sample spectral variability and controlling factors}

692 To investigate the ecological meaning of our results for wavelength dependence, we addressed the

693 variability in photosynthetic parameters outside of the population trends. This approach was based 694 on the detrended measurements of the PTA and RDA by wavelength, and the relationships between 695 the $\mathrm{E}_{\mathrm{k}}(\mathrm{II})$ ratios and their controlling factors. 
696 According to the PTA, the covariations observed among detrended values of photosynthetic

697 parameters and their change over the spectrum are consistent with wavelength dependence at the 698 population level of the parameters studied with the LMEMs. The PTA showed that the pattern of 699 the parameters changed gradually and consistently between blue and red wavelengths, concretely 700 for light absorption and photochemical quenching. Using the PTA to scan the intrastructure of the 70119 samples revealed also that spectral variation patterns of the parameters of each sample differed 702 from each other in size, shape and position on the factorial map. Sizes and shapes of these spectral 703 polygons were not related to water column stratification (e.g. the polygon of the most stratified 704 location (no. 33) was the same size as that of location 43, which was not stratified). According to 705 the RDA, photosynthetic parameters measured by wavelength were influenced mainly by euphotic 706 depth. The forward selection of the RDA first retained the most correlated variable in a group of 707 abiotic variables that covaried with biotic variables. Consequently, since the euphotic depth $\left(Z_{\mathrm{eu}}\right)$, 708 the light extinction coefficient $\left(\mathrm{K}_{\mathrm{d}(\mathrm{PAR})}\right)$ and the three light-quality ratios were collinear or 709 correlated variables (in the abiotic PCA), individual photosynthetic parameters could also be 710 controlled by the underwater light quality and turbidity, since the RDA also selected $\mathrm{K}_{\mathrm{d}(\mathrm{PAR})}$ and a 711 wavelength ratio. Considering all photosynthetic parameters, the main RDA result is thus 712 consistent with the significant relationship observed between the light saturation ratio $\left(\mathrm{E}_{\mathrm{k}}(\mathrm{II})_{625 / 440}\right)$ 713 and $\mathrm{R} / \mathrm{B}$ light ratio $\left(\mathrm{E}_{625 / 440}\right)$. The RDA also selected the TSS variable discussed later. Mixing 714 depth $\left(\mathrm{Z}_{\mathrm{umixl}}\right)$ was another interesting ecological parameter selected by the RDA. The RDA 715 confirms the hydrodynamic regime's control of the photoacclimation index $\mathrm{E}_{\mathrm{k}}$ previously 716 displayed by the relationship between $\mathrm{E}_{\mathrm{k}}\left(\mathrm{r}\right.$ and II) and $\mathrm{Z}_{\mathrm{eu}} / \mathrm{Z}_{\mathrm{umixl}}$. Since physical forcing in a given 717 upper mixed layer controls certainly the level reached by $E_{k}$, wavelength dependency of 718 photosynthetic parameters is generally a trade-off between the light quality of the different 719 encountered water masses and changes in light quantity throughout the upper mixed layer due to 720 the hydrodynamic regime. The RDA results and singular correlations with $\mathrm{E}_{\mathrm{k}}(\mathrm{r}$ and II) are 721 consistent, but the correlations of $\mathrm{E}_{\mathrm{k}}(\mathrm{II})_{625 / 440}$ with critical environmental parameters provide better 722 understanding of the ecological mechanisms that influence phytoplankton photoacclimation. The 723 results are interesting because they were obtained from the field, where light-quality ratios 724 (between red and blue wavelengths for instance) are known to change with depth (Supplementary 725 Material, Fig. S7, as also described by Brunet et al., (2014) and Jaubert et al., (2017). It is likely 726 that the influence of vertical changes in light-quality ratios on microalgae acclimation was small 
727 in the present study, especially because most upper mixed layers were shallow (6.5-14 m) and the

728 residence times of the cells at a given depth were low. The spectral light saturation ratios

$729 \mathrm{E}_{\mathrm{k}}(\mathrm{II})_{625 / 440}$ were therefore not correlated with the $\mathrm{Z}_{\mathrm{eu}} / \mathrm{Z}_{\mathrm{umixl}}$ index.

730 The significant correlations between $\mathrm{E}_{\mathrm{k}}(\mathrm{II})_{625 / 440}$ and $\mathrm{E}_{625 / 440}$ or TSS clearly highlight that natural

731 phytoplankton communities can implement photoacclimation processes that are driven by the in

732 situ light quality that also change during the daylight cycle. Most water masses had $\mathrm{E}_{625 / 440}$ ratios

733 less than 1, which indicates water in which blue wavelengths dominate red wavelengths, and

734 displayed higher $\mathrm{E}_{\mathrm{k}}(\mathrm{II})$ phytoplankton photoacclimation index in blue wavelengths than in red

735 wavelengths. This original result is valid only for absolute $\mathrm{E}_{\mathrm{k}}(\mathrm{II})_{\lambda}$ parameters related to Sigma(II) $)_{\lambda}$,

736 not for relative parameters r. $E_{k}$. Since Sigma(II) $)_{\lambda}$ measured with the MULTI-COLOR-PAM is an

737 intrinsic property of microalgae (Schreiber et al., 2012), and since microalgae can increase pigment

738 concentration to absorb more light (Lawrenz \& Richardson, 2017), differences in pigment

739 concentrations may change the level of Sigma(II $)_{\lambda}$ measured during the day. Due to the differing

740 variations in $r . E_{k}$ between blue and red wavelengths, $E_{k}(I I)_{625 / 440}$ ratios are therefore correlated

741 with $\mathrm{E}_{625 / 440}$ ratios in the water masses and with TSS, the time elapsed since sunrise. These

742 relationships provide new information about the natural environment and are consistent with many

743 experiments under controlled conditions. As several studies of monospecific cultures subjected to

744 contrasting R/B ratios show (Schellenberger Costa et al., 2013a; Brunet et al., 2014), variations in

745 the light spectrum and in blue vs. red wavelengths influence photoprotective capacity and the

746 pigment composition of phytoplankton. (Schellenberger Costa et al., 2013a) conclude that

747 photoprotection is regulated more by light quality (especially blue wavelengths) than by the overall

748 light intensity. Kirk (2011) stated that phytoplankton detect not so much the spectra of light, but

749 rather differences between wavelength ratios received by PSI and PSII, using blue and red

750 wavelength photoreceptors (Jaubert et al., 2017) that regulate photosynthesis and promote

751 photoacclimation (Schellenberger Costa et al., 2013b; Petroutsos et al., 2016). This explains why

752 the $\mathrm{E}_{\mathrm{k}}(\mathrm{II})$ for the green wavelength did not correlate significantly with the in situ light-quality

753 ratios of the green wavelengths. Photoacclimation mediation by in situ blue wavelengths, as

754 discussed by Schellenberger Costa et al., (2013a), is thus consistent with our field study.

755 The $\mathrm{E}_{\mathrm{k}}(\mathrm{II})_{625 / 440}$ vs. $\mathrm{E}_{625 / 440}$ correlation, like the abiotic PCA, indicates indirectly that variables

756 such as temperature, $\mathrm{PAR}_{2 \mathrm{~m}}$, and $\mathrm{DIN}$ and $\mathrm{Si}(\mathrm{OH})_{4}$ concentrations do not influence wavelength 
757 photoacclimation greatly. Previous studies in the EC showed that abiotic variables were the main 758 variables that controlled spatial and/or temporal variations in relative photosynthetic parameters 759 (Jouenne et al., 2007; Napoléon et al., 2013a; Houliez et al., 2015). However, the variables that 760 control these photosynthetic parameters may vary among geographic areas and/or seasons. In the present study, this correlation was determined over a large spatial scale.

\subsection{Ecological implications and consequences}

763 It is the general question of the absorption capacity of light in relation to the quality of light and 764 its impact on primary production that is discussed here.

765 The precise examination of the $\mathrm{E}_{\mathrm{k}}(\mathrm{II})_{625 / 440}$ versus $\mathrm{E}_{625 / 440}$ relationship in link with the reference 766 values of 1 indicates that the two ratios matched each other well. For example, at location 38, the $\mathrm{E}_{\mathrm{k}}(\mathrm{II})_{625 / 440}$ and $\mathrm{E}_{625 / 440}$ ratios equaled 1, which could be because the water there was sampled before sunrise. However, other communities sampled before sunrise (e.g. at locations 28, 46 and 53) showed imbalances in their $\mathrm{E}_{\mathrm{k}}(\mathrm{II})_{625 / 440}$ ratios related to the $\mathrm{E}_{625 / 440}$ ratios of water masses. The regression model indicates that to observe an $\mathrm{E}_{\mathrm{k}}(\mathrm{II})_{625 / 440}$ ratio of 1 , a theoretical $\mathrm{E}_{625 / 440}$ ratio of 1.29 would be required (which is close to our measurements). In this case, the blue wavelengths would decrease to $77 \mu$ molquanta. $\mathrm{m}^{-2} \cdot \mathrm{s}^{-1}$ given a red light of $100 \mu \mathrm{mol}$ quanta $\mathrm{m}^{-2} \cdot \mathrm{s}^{-1}$. Thus, the $\mathrm{E}_{625 / 440}$ ratio cited above indicates no strong imbalance in available energy and thus no stressful ecological situation for phytoplankton. In spring in temperate water, blue wavelengths are absorbed due to CDOM, in link with terrestrial discharge near estuaries and/or phytoplankton blooms themselves (Vantrepotte et al., 2007; Astoreca et al., 2009). Lawrenz \& Richardson (2017) studied photoacclimation under extreme conditions, with a total absence of blue light (i.e. black water with high CDOM concentrations). They showed that, depending on the taxon, microalgae retain or lose their initial light absorption capacity on the spectrum, and their absorption capacity adapts to the light quality to which they were exposed, even with red wavelengths. Some species can survive under red light in the short term, but in the long term, cytoplasmic structures and chloroplast membranes degrade (Humphrey, 1983) and Chla concentrations decline (Forster \& Dring, 1992). Rivkin (1989) showed the strong influence of blue light on carbon fixation and incorporation into amino acids and proteins. The $\mathrm{E}_{\mathrm{k}}(\mathrm{II})_{625 / 440} \mathrm{vs}$. $\mathrm{E}_{625 / 440}$ relationship in the present study cannot be extrapolated beyond the measurement limits (i.e. to the completely unbalanced 
786 light ratios of Lawrenz \& Richardson (2017)), but includes representative conditions generally

787 found in the EC or temperate systems.

788 In comparison, $\mathrm{E}_{\mathrm{k}}(\mathrm{II})_{625 / 440}$ ratios near 0 would indicate that blue wavelengths are ultra-dominant 789 in the water mass and could activate strong photoprotection mechanisms or even cause 790 photodamage, which would decrease $\operatorname{ETR}_{\max }$ (II) greatly under blue wavelengths. Under these 791 conditions, given the intercept of the linear model, $\mathrm{E}_{\mathrm{k}}$ (II) values under blue wavelengths would be 792 only $25 \%$ of those under the red wavelength, which suggests that primary production would 793 decrease greatly. However, electron flows under green, amber and light red wavelengths remained 794 high, and NPQ was not as strong as under blue wavelengths. These results were consistent with 795 the low light absorption (Sigma(II) $)_{\lambda}$ ) under these wavelengths, as was the NPQ. However, this 796 raises the issue of using the spectral approach to calculate primary production based on the 797 photosynthetic parameters of RLC relationships.

798 Previous studies of the wavelength dependence of photosynthesis specified the systematic error 799 produced by measuring $\alpha$ under white-light incubators when comparing incubation light climates 800 (Laws et al., 1990) or primary production models (Kyewalyanga et al., 1992). Most classic 801 incubators do not reproduce light spectra at the low intensities that phytoplankton encounter in the 802 water column because of the high variability in light quality with depth, but also with time, due to 803 vertical mixing in the upper part of the water column. Schofield et al., (1996) examined the error 804 caused by using the same or different $\alpha$ from cultures grown under different light qualities when 805 calculating primary production in a theoretical and simplified water column. Depending on the 806 species and growing conditions, differences between vertical primary production rates estimated 807 by the two calculation methods ranged from 12-49\%. Other studies showed that $\alpha$ values measured 808 on board under artificial light (Irwin et al., 1990) could be corrected from the shape of the 809 phytoplankton absorption spectrum (Kyewalyanga et al., 1997; Sathyendranath et al., 1999). This 810 approach involves the field of remote sensing in particular and includes "optical" and "full 811 spectral" models (Platt \& Sathyendranath, 1988; Sathyendranath \& Platt, 1993; Behrenfeld \& 812 Falkowski, 1997). Recent studies (Kovač et al., 2017; Sathyendranath et al., 2020) combined a 813 spectral model of underwater light with a model of the integrated spectral response of algal 814 photosynthesis consistent with photoacclimation processes. These studies recommend using the 815 photosynthesis action spectrum or spectral correction of $\alpha$ in the water column, especially when 
816 differences in the shape of the action spectrum of $\alpha$ are larger than those in its magnitude at each

817 wavelength (Sathyendranath \& Platt, 1993). However, these studies did not consider that light-

818 quality ratios in surface water can also greatly influence photoacclimation of microalgae. This was

819 revealed in the present study by some individual wavelength-dependence phenomenon that

820 differed significantly among the samples, and the $\mathrm{E}_{\mathrm{k}}(\mathrm{II})_{625 / 440}$ ratios, which involve $\mathrm{ETR}_{\max }(\mathrm{II})$ and

$821 \alpha($ II) (i.e. the photosynthetic apparatus), especially the functional absorption cross section of PSII

822 and the maximum rate of $\mathrm{PET}_{\lambda}$, according to the optical definition of $\mathrm{E}_{\mathrm{k}}$ (Falkowski \& Raven,

823 2007). Parameters $\alpha(\text { II) and Sigma(II) })_{\lambda}$ showed no significant individual wavelength dependence

824 among water masses, unlike $\mathrm{ETR}_{\max }(\mathrm{II})$ and $\mathrm{E}_{\mathrm{k}}(\mathrm{II})$, which are involved in primary production at

825 high light intensities. The central issue is thus how photosynthetic activity induced by wavelengths

826 beyond $480 \mathrm{~nm}$ can compensate for the decrease in photosynthesis under strong blue light when

827 estimating primary production in different water masses. Sensitivity analysis of physicochemical

828 properties of water would pave the way for future research on wavelength dependence of

829 phytoplankton photosynthesis, as well as spectral dependence at the seasonal scale, using current

830 active fluorescence measurement technologies.

831

832 Conclusion

833 Our results indicate that natural phytoplankton communities can photoacclimate to light quality

834 dynamically under contrasting environmental conditions in temperate coastal seas in response to

835 the available energy balance between red and blue wavelengths. The wavelength dependence of

836 photosynthetic parameters was here characterized at the population level (in a consistent way with

837 the photosynthesis theory) and at the sample level where a high spatio-temporal variability was

838 observed. The photosynthetic parameters $E_{k}, E R_{\max }$ (both in relative and absolute units) and

839 NPQ proved to be here the most important ones for understanding the photoacclimation dynamics

840 of natural microalgae communities. With a general model of photoprotection against blue light

841 based on NPQ of photosynthesis, the present study shows that natural phytoplankton communities

842 were most adapted to high-intensity light when a large amount of light was absorbed (e.g. blue

843 wavelengths) but appeared "shade" adapted when low-intensity light was absorbed (e.g. green,

844 amber and light red wavelengths), to paraphrase Nielsen \& Sakshaug (1993). 
845 The results for dynamic photoacclimation processes showed a general trade-off between light 846 quality and intensity, and also all related light factors (e.g. $\mathrm{K}_{\mathrm{d}(\mathrm{PAR})}, \mathrm{Z}_{\mathrm{eu}}, \mathrm{Z}_{\mathrm{umixl}}$ ), which is difficult 847 to find in experimental studies, through which photoacclimation has been discussed for many years

848 (Schofield, Prezelin \& Johnsen, 1996; Brunet et al., 2014; Gorai et al., 2014). Experimental studies 849 are generally performed with monocultures growing in the comfort of laboratories for generations 850 and rarely with natural communities using conventional photosynthetic parameters. These cultures 851 are subjected to photon flux of different wavelengths and/or intensities, with different frequencies 852 of variation, different daylight cycles, etc. Experiments often consider the controlling variables 853 separately but combining them simultaneously seems relevant for understanding processes of 854 photoacclimation to light variations in the field, as discussed by Combe et al., (2015) in a modeling 855 study.

856

\section{Acknowledgements}

858 The authors thank Dr L.F. Artigas that conceived and led the field campaign (ECOPEL-2018), the 859 captains and the crews on board the R/V «ANTEA » for assistance, as well as the technical staffs 860 of CNRS-LOG. The field campaign was carried out thanks to the convention ( $\left.\mathrm{n}^{\circ} 2101893310\right)$ 861 between the French Ministry for the Ecological and Inclusive Transition and the CNRS for the 862 implementation of the Marine Strategy Framework Directive (MSFD). This study is also integrated 863 into the European project H2020 JERICO-NEXT. 


\section{References}

866 Alderkamp A-C, Garcon V, de Baar HJW, Arrigo KR. 2011. Short-term photoacclimation effects on photoinhibition of phytoplankton in the Drake Passage (Southern Ocean). Deep Sea Research Part I: Oceanographic Research Papers 58:943-955. DOI:

Alderkamp A-C, Mills MM, Dijken GL van, Arrigo KR. 2013. Photoacclimation and nonphotochemical quenching under in situ irradiance in natural phytoplankton assemblages from the Amundsen Sea, Antarctica. Marine Ecology Progress Series 475:15-34. DOI:

Aminot A, Kérouel R. 2004. Hydrologie des écosystèmes marins: paramètres et analyses. $10.3354 /$ meps 10097 .

Anning T, Harris G, Geider R. 2001. Thermal acclimation in the marine diatom Chaetoceros calcitrans (Bacillariophyceae). European Journal of Phycology 36:233-241. DOI: 10.1080/09670260110001735388.

Anning T, MacIntyre HL, Pratt SM, Sammes PJ, Gibb S, Geider RJ. 2000. Photoacclimation in the marine diatom Skeletonema costatum. Limnology and Oceanography 45:1807-1817. DOI: $10.4319 / 10.2000 .45 .8 .1807$.

Baker NR, Bowyer JR. 1994. Photoinhibition of Photosynthesis: From Molecular Mechanisms to 886 the Field. BIOS Scientific Publishers. 
887 Barlow R, Lamont T, Britz K, Sessions H. 2013. Mechanisms of phytoplankton adaptation to 888 environmental variability in a shelf ecosystem. Estuarine, Coastal and Shelf Science 889 133:45-57. DOI: 10.1016/j.ecss.2013.08.006.

890 Barlow R, Lamont T, Gibberd M-J, Airs R, Jacobs L, Britz K. 2017. Phytoplankton communities 891 892 and acclimation in a cyclonic eddy in the southwest Indian Ocean. Deep Sea Research Part I: Oceanographic Research Papers 124:18-30. DOI: 10.1016/j.dsr.2017.03.013.

Bates D, Mächler M, Bolker B, Walker S. 2015. Fitting Linear Mixed-Effects Models Using Ime4. Journal of Statistical Software 67. DOI: 10.18637/jss.v067.i01.

Bates D, Maechler M, Bolker B, Walker S, Christensen RHB, Singmann H, Dai B, Scheipl F, Grothendieck G, Green P, Fox J. 2019. Ime4: Linear Mixed-Effects Models using “Eigen” and $S 4$.

Behrenfeld MJ, Falkowski PG. 1997. A consumer's guide to phytoplankton primary productivity models. Limnology and Oceanography 42:1479-1491. DOI: 10.4319/1o.1997.42.7.1479.

Beutler M, Wiltshire KH, Meyer B, Moldaenke C, Lüring C, Meyerhöfer M, Hansen U-P, Dau H. 901 902 2002. A fluorometric method for the differentiation of algal populations in vivo and in situ. Photosynthesis Research 72:39-53. DOI: 10.1023/A:1016026607048.

Bidigare RR, Ondrusek ME, Morrow JH, Kiefer DA. 1990. In-vivo absorption properties of algal 904 pigments. In: Spinrad RW ed. Orlando, FL, United States, 290. DOI: 10.1117/12.21451.

Bilger W, Björkman O. 1990. Role of the xanthophyll cycle in photoprotection elucidated by 906 907 measurements of light-induced absorbance changes, fluorescence and photosynthesis in leaves of Hedera canariensis. Photosynthesis Research 25:173-185. DOI: 908 10.1007/BF00033159. 
909 Björkman O, Demmig B. 1987. Photon yield of O2 evolution and chlorophyll fluorescence $910 \quad$ characteristics at $77 \mathrm{~K}$ among vascular plants of diverse origins. Planta 170:489-504. DOI:

$911 \quad$ 10.1007/BF00402983.

912 Brunet C, Brylinski J, Lemoine Y. 1993. In situ variations of the xanthophylls diatoxanthin and 913 diadinoxanthin: photoadaptation and relationships with a hydrodynamical system in the 914 eastern English Channel. Marine Ecology Progress Series 102:69-77. DOI: $915 \quad 10.3354 /$ meps 102069.

916 Brunet C, Chandrasekaran R, Barra L, Giovagnetti V, Corato F, Ruban AV. 2014. Spectral 917 Radiation Dependent Photoprotective Mechanism in the Diatom Pseudo-nitzschia 918 multistriata. PLoS ONE 9:e87015. DOI: 10.1371/journal.pone.0087015.

919 Brunet C, Lavaud J. 2010. Can the xanthophyll cycle help extract the essence of the microalgal 920 functional response to a variable light environment? Journal of Plankton Research 32:1609-1617. DOI: 10.1093/plankt/fbq104.

Brunet C, Lizon F. 2003. Tidal and diel periodicities of size-fractionated phytoplankton pigment signatures at an offshore station in the southeastern English Channel. Estuarine, Coastal and Shelf Science 56:833-843. DOI: 10.1016/S0272-7714(02)00323-2. Auger Y, Puskaric E, Wartel M, Cabioch L. 1991. Le “fleuve côtier”: Un phénomène 927 hydrologique important en Manche orientale (exemple du Pas de Calais). Oceanol. Acta 928 11:197-203.

Burson A, Stomp M, Greenwell E, Grosse J, Huisman J. 2018. Competition for nutrients and light: testing advances in resource competition with a natural phytoplankton community. Ecology 99:1108-1118. DOI: 10.1002/ecy.2187. 
932 Burson A, Stomp M, Mekkes L, Huisman J. 2019. Stable coexistence of equivalent nutrient 933 competitors through niche differentiation in the light spectrum. Ecology 100. DOI: 10.1002/ecy.2873.

935 Claquin P, NÍ Longphuirt S, Fouillaron P, Huonnic P, Ragueneau O, Klein C, Leynaert A. 2010. 936 Effects of simulated benthic fluxes on phytoplankton dynamic and photosynthetic parameters in a mesocosm experiment (Bay of Brest, France). Estuarine, Coastal and Shelf Science 86:93-101. DOI: 10.1016/j.ecss.2009.10.017.

939 Combe C, Hartmann P, Rabouille S, Talec A, Bernard O, Sciandra A. 2015. Long-term adaptive response to high-frequency light signals in the unicellular photosynthetic eukaryote Dunaliella salina. Biotechnology and Bioengineering 112:1111-1121. DOI: https://doi.org/10.1002/bit.25526.

Correa-Reyes JG, Sánchez-Saavedra M del P, Siqueiros-Beltrones DA, Flores-Acevedo N. 2001.

Dimier C, Corato F, Tramontano F, Brunet C. 2007. Photoprotection and xanthophyll-cycle activity in three marine diatoms1. Journal of Phycology 43:937-947. DOI: 10.1111/j.15298817.2007.00381.x.

Dimier C, Giovanni S, Ferdinando T, Brunet C. 2009. Comparative Ecophysiology of the 950 Xanthophyll Cycle in Six Marine Phytoplanktonic Species. Protist 160:397-411. DOI: 10.1016/j.protis.2009.03.001.

952

Dougher TAO, Bugbee B. 2001. Differences in the Response of Wheat, Soybean and Lettuce to 953 Reduced Blue Radiation $\uparrow$. Photochemistry and Photobiology 73:199-207. DOI: 10.1562/0031-8655(2001)073<0199:DITROW>2.0.CO;2. 
955 Dray S, Dufour A-B, Thioulouse and J, Jombart with contributions from T, Pavoine S, Lobry JR, 956 Ollier S, Borcard D, Legendre P, Chessel SB and ASB on earlier work by D. 2018. ade4: Analysis of Ecological Data: Exploratory and Euclidean Methods in Environmental Sciences.

Dubinsky Z, Schofield O. 2010. From the light to the darkness: thriving at the light extremes in 960 the oceans. Hydrobiologia 639:153-171. DOI: 10.1007/s10750-009-0026-0.

961 Dubinsky Z, Stambler N. 2009. Photoacclimation processes in phytoplankton: mechanisms, 962 963 consequences, and applications. Aquatic Microbial Ecology 56:163-176. DOI: 10.3354/ame01345.

Eilers PHC, Peeters JCH. 1988. A model for the relationship between light intensity and the rate of photosynthesis in phytoplankton. Ecological Modelling 42:199-215. DOI: $10.1016 / 0304-3800(88) 90057-9$.

967 Engelmann TW. 1883. Farbe und Assimilation. Bot. Zeit 41:1-13,17-29.

968 Falkowski PG, Knoll AH. 2007. An Introduction to Primary Producers in the Sea: Who They Are, 969 What They Do, and When They Evolved. In: Evolution of Primary Producers in the Sea. Elsevier, 1-6. DOI: 10.1016/B978-012370518-1/50002-3.

Falkowski PG, LaRoche J. 1991. Acclimation to Spectral Irradiance in Algae. Journal of 973 Phycology 27:8-14. DOI: 10.1111/j.0022-3646.1991.00008.x.

Falkowski PG, Raven JA. 2007. Aquatic photosynthesis. Princeton: Princeton University Press.

974 Forster RM, Dring MJ. 1992. Interactions of blue light and inorganic carbon supply in the control 975 of light-saturated photosynthesis in brown algae. Plant, Cell \& Environment 15:241-247. DOI: 10.1111/j.1365-3040.1992.tb01478.x. 
977 From N, Richardson K, Mousing EA, Jensen PE. 2014. Removing the light history signal from 978 normalized variable fluorescence $\left(\mathrm{F}_{\mathrm{v}} / \mathrm{F}_{\mathrm{m}}\right)$ measurements on marine phytoplankton. 979 Limnology and Oceanography: Methods 12:776-783. DOI: 10.4319/lom.2014.12.776.

980 Gentilhomme V, Lizon F. 1998. Seasonal cycle of nitrogen and phytoplankton biomass in a well981 mixed coastal system (Eastern English Channel). Hydrobiologia 361:191-199. DOI: $982 \quad 10.1023 / \mathrm{A}: 1003134617808$.

983 Goessling JW, Cartaxana P, Kühl M. 2016. Photo-Protection in the Centric Diatom Coscinodiscus 984 985 granii is Not Controlled by Chloroplast High-Light Avoidance Movement. Frontiers in Marine Science 2. DOI: 10.3389/fmars.2015.00115.

986 Goessling J, Frankenbach S, Ribeiro L, Serôdio J, Kühl M. 2018a. Modulation of the light field 987 related to valve optical properties of raphid diatoms: implications for niche differentiation 988 in the microphytobenthos. Marine Ecology Progress Series 588:29-42. DOI: $10.3354 /$ meps 12456.

990 Goessling JW, Su Y, Cartaxana P, Maibohm C, Rickelt LF, Trampe ECL, Walby SL, 991 992 Wangpraseurt D, Wu X, Ellegaard M, Kühl M. 2018b. Structure-based optics of centric diatom frustules: modulation of the in vivo light field for efficient diatom photosynthesis. 993 New Phytologist 219:122-134. DOI: 10.1111/nph.15149.

994 Gorai T, Katayama T, Obata M, Murata A, Taguchi S. 2014. Low blue light enhances growth rate, 995 light absorption, and photosynthetic characteristics of four marine phytoplankton species. Journal of Experimental Marine Biology and Ecology 459:87-95. DOI: 10.1016/j.jembe.2014.05.013.

998 Gorbunov M, Shirsin E, Nikonova E, Fadeev V, Falkowski P. 2020. A multi-spectral fluorescence 999 induction and relaxation (FIRe) technique for physiological and taxonomic analysis of 
1000

1001

1002

1003

1004

1005

1006

1007

1008

1009

1010

1011

1012

1013

1014

1015

1016

1017

1018

1019

1020

1021

phytoplankton communities. Marine Ecology Progress Series 644:1-13. DOI: $10.3354 /$ meps 13358 .

Herbstová M, Bína D, Koník P, Gardian Z, Vácha F, Litvín R. 2015. Molecular basis of chromatic adaptation in pennate diatom Phaeodactylum tricornutum. Biochimica et Biophysica Acta (BBA) - Bioenergetics 1847:534-543. DOI: 10.1016/j.bbabio.2015.02.016.

Hickman A, Dutkiewicz S, Williams R, Follows M. 2010. Modelling the effects of chromatic adaptation on phytoplankton community structure in the oligotrophic ocean. Marine Ecology Progress Series 406:1-17. DOI: 10.3354/meps08588.

Hickman AE, Holligan PM, Moore CM, Sharples J, Krivtsov V, Palmer MR. 2009. Distribution and chromatic adaptation of phytoplankton within a shelf sea thermocline. Limnology and Oceanography 54:525-536. DOI: 10.4319/1o.2009.54.2.0525.

Honaker J, King G, Blackwell M. 2018. Amelia: A Program for Missing Data.

Houliez E, Lizon F, Artigas LF, Lefebvre S, Schmitt FG. 2013a. Spatio-temporal variability of phytoplankton photosynthetic activity in a macrotidal ecosystem (the Strait of Dover, eastern English Channel). Estuarine, Coastal and Shelf Science 129:37-48. DOI: 10.1016/j.ecss.2013.06.009.

Houliez E, Lizon F, Lefebvre S, Artigas LF, Schmitt FG. 2013b. Short-term variability and control of phytoplankton photosynthetic activity in a macrotidal ecosystem (the Strait of Dover, eastern English Channel). Marine Biology 160:1661-1679. DOI: 10.1007/s00227-013$2218-4$

Houliez E, Lizon F, Lefebvre S, Artigas LF, Schmitt FG. 2015. Phytoplankton photosynthetic activity dynamics in a temperate macrotidal ecosystem (the Strait of Dover, eastern English 
1022

1023

1024

1025

1026

1027

1028

1029

1030

1031

1032

1033

1034

1035

1036

1037

1038

1039

1040

1041

1042

Channel): Time scales of variability and environmental control. Journal of Marine Systems 147:61-75. DOI: 10.1016/j.jmarsys.2014.05.001.

Houliez E, Lizon F, Thyssen M, Artigas LF, Schmitt FG. 2012. Spectral fluorometric characterization of Haptophyte dynamics using the FluoroProbe: an application in the eastern English Channel for monitoring Phaeocystis globosa. Journal of Plankton Research 34:136-151. DOI: 10.1093/plankt/fbr091.

Houliez E, Simis S, Nenonen S, Ylöstalo P, Seppälä J. 2017. Basin-scale spatio-temporal variability and control of phytoplankton photosynthesis in the Baltic Sea: The first multiwavelength fast repetition rate fluorescence study operated on a ship-of-opportunity. Journal of Marine Systems 169:40-51. DOI: 10.1016/j.jmarsys.2017.01.007.

Humphrey GF. 1983. The effect of the spectral composition of light on the growth, pigments, and photosynthetic rate of unicellular marine algae. Journal of Experimental Marine Biology and Ecology 66:49-67. DOI: 10.1016/0022-0981(83)90027-8.

Husson F, Josse J, Le S, Mazet J. 2020. FactoMineR: Multivariate Exploratory Data Analysis and Data Mining.

Irwin B, Anning J, Caverhill C, Platt T. 1990. Primary production on the Labrador Shelf and the Strait of Belle Isle in May 1988. P.O. Box 1006 Darmouth, Nova Scotia: Bedford Institute of Oceanography.

Jaubert M, Bouly J-P, Ribera d'Alcalà M, Falciatore A. 2017. Light sensing and responses in marine microalgae. Current Opinion in Plant Biology 37:70-77. DOI: 10.1016/j.pbi.2017.03.005.

Peer) reviewing PDF | (2020:12:56632:2:0:NEW 22 Jul 2021) 
1043 Jeffrey SW, Wright SW, Zapata M. 2011. Microalgal classes and their signature pigments. In: Roy

1044 S, Llewellyn C, Egeland ES, Johnsen G eds. Phytoplankton Pigments. Cambridge:

1045 Cambridge University Press, 3-77. DOI: 10.1017/CBO9780511732263.004.

1046 Jensen JP, Jeppesen E, Olrik K, Kristensen P. 1994. Impact of Nutrients and Physical Factors on 1047 the Shift from Cyanobacterial to Chlorophyte Dominance in Shallow Danish Lakes. 1048 Canadian Journal of Fisheries and Aquatic Sciences. DOI: 10.1139/f94-170.

1049 Jouenne F, Lefebvre S, Véron B, Lagadeuc Y. 2005. Biological and physicochemical factors 1050 controlling short-term variability in phytoplankton primary production and photosynthetic 1051 parameters in a macrotidal ecosystem (eastern English Channel). Estuarine, Coastal and 1052 Shelf Science 65:421-439. DOI: 10.1016/j.ecss.2005.05.023.

1053 Jouenne F, Lefebvre S, Véron B, Lagadeuc Y. 2007. Phytoplankton community structure and 1054 primary production in small intertidal estuarine-bay ecosystem (eastern English Channel, 1055 France). Marine Biology 151:805-825. DOI: 10.1007/s00227-006-0440-z.

1056 Kehoe DM, Gutu A. 2006. Responding to Color: The Regulation of Complementary Chromatic 1057 Adaptation. Annual Review of Plant Biology 57:127-150. DOI: 10.1146/annurev.arplant.57.032905.105215.

Kirk JTO. 2011. Light and Photosynthesis in Aquatic Ecosystems. Cambridge: Cambridge $1060 \quad$ University Press. DOI: 10.1017/CBO9781139168212.

1061 Klughammer C, Schreiber U. 2015. Apparent PS II absorption cross-section and estimation of 1062 1063 mean PAR in optically thin and dense suspensions of Chlorella. Photosynthesis Research 123:77-92. DOI: 10.1007/s11120-014-0040-6. 
1064 Kovač Ž, Platt T, Sathyendranath S, Antunović S. 2017. Models for estimating photosynthesis 1065 parameters from in situ production profiles. Progress in Oceanography 159:255-266. DOI: $1066 \quad$ 10.1016/j.pocean.2017.10.013.

1067 Kuczynska P, Jemiola-Rzeminska M, Strzalka K. 2015. Photosynthetic Pigments in Diatoms. 1068 Marine Drugs 13:5847-5881. DOI: 10.3390/md13095847.

1069 Kyewalyanga M, Piatt T, Sathyendrath S. 1992. Ocean primary production calculated by spectral 1070 and broad-band models. Marine Ecology Progress Series 85:171-185. DOI:

1071 $10.3354 /$ meps085171.

1072 Kyewalyanga M, Platt T, Sathyendranath S. 1997. Estimation of the photosynthetic action 1073

1074 spectrum:implication for primary production models. Marine Ecology Progress Series 146:207-223. DOI: 10.3354/meps146207.

1075 Kyewalyanga M, Sathyendranath S, Platt T. 2002. Effect of Mesodinium rubrum (= Myrionecta 1076 rubra) on the action and absorption spectra of phytoplankton in a coastal marine inlet. Journal of Plankton Research 24:687-702. DOI: 10.1093/plankt/24.7.687.

1078 Lavaud J. 2007. Fast Regulation of Photosynthesis in Diatoms: Mechanisms, Evolution and 1079 Ecophysiology. Functional Plant Science and Biotechonology 1:267-287.

1080 Lavit C, Escoufier Y, Sabatier R, Traissac P. 1994. The ACT (STATIS method). Computational $1081 \quad$ Statistics \& Data Analysis 18:97-119. DOI: 10.1016/0167-9473(94)90134-1.

1082 Lawrenz E, Richardson TL. 2017. Differential effects of changes in spectral irradiance on 1083 photoacclimation, primary productivity and growth in Rhodomonas salina 1084 (Cryptophyceae) and Skeletonema costatum (Bacillariophyceae) in simulated blackwater 1085 environments. Journal of Phycology 53:1241-1254. DOI: 10.1111/jpy.12578. 
1086 Laws EA, DiTullio GR, Carder KL, Betzer PR, Hawes S. 1990. Primary production in the deep 1087 blue sea. Deep Sea Research Part A. Oceanographic Research Papers 37:715-730. DOI: $1088 \quad 10.1016 / 0198-0149(90) 90001-C$.

1089 Lefebvre S, Mouget J-L, Lavaud J. 2011. Duration of rapid light curves for determining the 1090 photosynthetic activity of microphytobenthos biofilm in situ. Aquatic Botany 95:1-8. DOI: $1091 \quad$ 10.1016/j.aquabot.2011.02.010.

1092 Legendre P, Legendre L. 2012. Numerical ecology. Amsterdam: Elsevier.

1093 Lewis MR, Ulloa O, Platt T. 1988. Photosynthetic action, absorption, and quantum yield spectra 1094 for a natural population of Oscillatoria in the North Atlantic1. Limnology and 1095 Oceanography 33:92-98. DOI: 10.4319/lo.1988.33.1.0092.

1096 Lewis MR, Warnock RE, Irwin B, Platt T. 1985. Measuring Photosynthetic Action Spectra of 1097 Natural Phytoplankton Populations. Journal of Phycology 21:310-315. DOI: $1098 \quad 10.1111 / \mathrm{j} .0022-3646.1985 .00310 . x$.

1099 Lewis MR, Warnock RE, Platt T. 1985. Absorption and photosynthetic action spectra for natural 1100 phytoplankton populations: Implications for production in the open ocean1: Spectral 1101 photosynthesis. Limnology and Oceanography 30:794-806. DOI: $1102 \quad 10.4319 /$ lo.1985.30.4.0794.

1103 Lowe J, Howard T, Pardaens A, Tinker J, Holt J, Wakelin S, Milne G, Leake J, Wolf J, Horsburgh 1104 K, Reeder T, Jenkins G, Ridley J, Dye S, Bradley S. 2009.UK Climate Projections Science 1105 Report: Marine and Coastal Projections. Available at 1106 http://ukclimateprojections.defra.gov.uk/media.jsp? mediaid=87850\&filetype $=p d f$ 1107 (accessed December 1, 2020). 
1108 Luimstra VM, Schuurmans JM, de Carvalho CFM, Matthijs HCP, Hellingwerf KJ, Huisman J.

1109 2019. Exploring the low photosynthetic efficiency of cyanobacteria in blue light using a

1110 mutant lacking phycobilisomes. Photosynthesis Research 141:291-301. DOI:

$1111 \quad$ 10.1007/s11120-019-00630-z.

1112 Luimstra VM, Schuurmans JM, Verschoor AM, Hellingwerf KJ, Huisman J, Matthijs HCP. 2018.

1113 Blue light reduces photosynthetic efficiency of cyanobacteria through an imbalance

1114 between photosystems I and II. Photosynthesis Research 138:177-189. DOI:

$1115 \quad 10.1007 / \mathrm{s} 11120-018-0561-5$.

1116 Luimstra VM, Verspagen JMH, Xu T, Schuurmans JM, Huisman J. 2020. Changes in water color

1117 shift competition between phytoplankton species with contrasting light-harvesting $1118 \quad$ strategies. Ecology. DOI: 10.1002/ecy.2951.

1119 MacIntyre HL, Kana TM, Anning T, Geider RJ. 2002. Photoacclimation of photosynthesis $1120 \quad$ irradiance response curves and photosynthetic pigments in microalgae and cyanobacteria. 1121 Journal of Phycology 38:17-38. DOI: 10.1046/j.1529-8817.2002.00094.x.

1122 MacIntyre HL, Kana TM, Geider RJ. 2000. The effect of water motion on short-term rates of

1123 photosynthesis by marine phytoplankton. Trends in Plant Science 5:12-17. DOI: $1124 \quad 10.1016 / \mathrm{S} 1360-1385(99) 01504-6$.

1125 Mendes S, Fernández-Gómez MJ, Jorge Pereira M, Azeiteiro U, Galindo Villardón MP. 2010.

1126 The efficiency of the Partial Triadic Analysis method: an ecological application. $1127 \quad$ Biometrical Letters 47:83-106.

1128 Mercado JM, del Pilar Sánchez-Saavedra M, Correa-Reyes G, Lubián L, Montero O, Figueroa FL. 1129 2004. Blue light effect on growth, light absorption characteristics and photosynthesis of 
five benthic diatom strains. Aquatic Botany 78:265-277. DOI: 10.1016/j.aquabot.2003.11.004.

1132 Napoléon C, Fiant L, Raimbault V, Claquin P. 2013a. Study of dynamics of phytoplankton and 1133 photosynthetic parameters using opportunity ships in the western English Channel. Journal 1134 of Marine Systems 128:146-158. DOI: 10.1016/j.jmarsys.2013.04.019.

1135 Napoléon C, Raimbault V, Claquin P. 2013b. Influence of Nutrient Stress on the Relationships 1136 between PAM Measurements and Carbon Incorporation in Four Phytoplankton Species. PLoS ONE 8:e66423. DOI: 10.1371/journal.pone.0066423.

1138 Nielsen MV, Sakshaug E. 1993. Photobiological studies of Skeletonema costatum adapted to 1139 spectrally different light regimes. Limnology and Oceanography 38:1576-1581. DOI: 10.4319/1o.1993.38.7.1576.

1141 Oksanen J, Blanchet FG, Friendly M, Kindt R, Legendre P, McGlinn D, Minchin PR, O’Hara RB,

1142 Simpson GL, Solymos P, Stevens MHH, Szoecs E, Wagner H. 2019. vegan: Community 1143 Ecology Package.

1144 Orefice I, Chandrasekaran R, Smerilli A, Corato F, Caruso T, Casillo A, Corsaro MM, Piaz FD, 1145 Ruban AV, Brunet C. 2016. Light-induced changes in the photosynthetic physiology and 1146 biochemistry in the diatom Skeletonema marinoi. Algal Research 17:1-13. DOI: $1147 \quad$ 10.1016/j.algal.2016.04.013.

1148 Painter SC, Lucas MI, Stinchcombe MC, Bibby TS, Poulton AJ. 2010. Summertime trends in 1149 pelagic biogeochemistry at the Porcupine Abyssal Plain study site in the northeast Atlantic. 1150 Deep Sea Research Part II: Topical Studies in Oceanography 57:1313-1323. DOI: $1151 \quad$ 10.1016/j.dsr2.2010.01.008. 
1152 Petroutsos D, Tokutsu R, Maruyama S, Flori S, Greiner A, Magneschi L, Cusant L, Kottke T,

1153 Mittag M, Hegemann P, Finazzi G, Minagawa J. 2016. A blue-light photoreceptor mediates

1154 the feedback regulation of photosynthesis. Nature 537:563-566. DOI:

$1155 \quad 10.1038 /$ nature19358.

1156 Pinheiro JC, Bates DM. 2000. Mixed-effects models in S and S-PLUS. New York: Springer.

1157 Platt T, Jassby AD. 1976. The relationship between photosynthesis and light for natural 1158 assamblages of coastal marine phytoplankton. Journal of Phycology 12:421-430. DOI: $1159 \quad 10.1111 / \mathrm{j} .1529-8817.1976 . t b 02866 . x$.

1160 Platt T, Sathyendranath S. 1988. Oceanic Primary Production: Estimation by Remote Sensing at 1161 Local and Regional Scales. Science 241:1613-1620. DOI: $1162 \quad$ 10.1126/science.241.4873.1613.

1163 Premvardhan L, Sandberg DJ, Fey H, Birge RR, Büchel C, van Grondelle R. 2008. The Charge-

1164 Transfer Properties of the $\mathrm{S}_{2}$ State of Fucoxanthin in Solution and in Fucoxanthin 1165 Chlorophyll-a/c 2 Protein (FCP) Based on Stark Spectroscopy and Molecular-Orbital 1166 Theory. The Journal of Physical Chemistry B 112:11838-11853. DOI: $1167 \quad 10.1021 / j p 802689 p$.

1168 R Core Team. 2020.R: A language and environment for statistical computing. R Foundation for 1169 statistica Computing. Available at https://www.r-project.org/ (accessed December 1, $1170 \quad 2020)$.

1171 Riley GA. 1957. Phytoplankton of the North Central Sargasso Sea, 1950-521. Limnology and 1172 Oceanography 2:252-270. DOI: 10.1002/lno.1957.2.3.0252. 
1173 Rivkin R. 1989. Influence of irradiance and spectral quality on the carbon metabolism of

1174 phytoplankton I. Photosynthesis, chemical composition and growth. Marine Ecology

1175 Progress Series 55:291-304. DOI: 10.3354/meps055291.

1176 Sathyendranath S, Platt T. 1993. Remote senting of water-colum primary production. In: 237-243.

1177 Sathyendranath S, Platt T, Kovač Ž, Dingle J, Jackson T, Brewin RJW, Franks P, Marañón E, Kulk

1178 G, Bouman HA. 2020. Reconciling models of primary production and photoacclimation

1179 [Invited]. Applied Optics 59:C100. DOI: 10.1364/AO.386252.

1180 Sathyendranath S, Stuart V, Irwin BD, Maass H, Savidge G, Gilpin L, Platt T. 1999. Seasonal

1181 variations in bio-optical properties of phytoplankton in the Arabian Sea. Deep Sea

1182 Research Part II: Topical Studies in Oceanography 46:633-653. DOI: 10.1016/S0967-

$1183 \quad$ 0645(98)00121-0.

1184 Schellenberger Costa B, Jungandreas A, Jakob T, Weisheit W, Mittag M, Wilhelm C. 2013a. Blue

1185 light is essential for high light acclimation and photoprotection in the diatom

1186 Phaeodactylum tricornutum. Journal of Experimental Botany 64:483-493. DOI:

$1187 \quad 10.1093 / \mathrm{j} x \mathrm{~b} / \mathrm{ers} 340$.

1188 Schellenberger Costa B, Sachse M, Jungandreas A, Bartulos CR, Gruber A, Jakob T, Kroth PG,

1189 Wilhelm C. 2013b. Aureochrome 1a Is Involved in the Photoacclimation of the Diatom

$1190 \quad$ Phaeodactylum tricornutum. PLoS ONE 8:e74451. DOI: 10.1371/journal.pone.0074451.

1191 Schofield O, Moline M, Cahill B, Frazer T, Kahl A, Oliver M, Reinfelder J, Glenn S, Chant R.

1192 2013. Phytoplankton productivity in a turbid buoyant coastal plume. Continental Shelf

1193 Research 63:S138-S148. DOI: 10.1016/j.csr.2013.02.005.

1194 Schofield O, Prezelin B, Johnsen G. 1996. Wavelength dependency of the maximum quantum

1195 yield of carbon fixation for two red tide dinoflagellates, Heterocapsa pygmaea and 
1196

1197

1198

1199

1200

1201

1202

1203

1204

1205

1206

1207

1208

1209

1210

1211

1212

1213

1214

1215

1216

1217

1218

Prorocentrum minimum (pyrrophyta): Implications for measuring photosynthetic rates. Journal of Phycology 32:574-583. DOI: 10.1111/j.0022-3646.1996.00574.x.

Schreiber U, Klughammer C. 2013. Wavelength-dependent photodamage to Chlorella investigated with a new type of multi-color PAM chlorophyll fluorometer. Photosynthesis Research 114:165-177. DOI: 10.1007/s11120-013-9801-x.

Schreiber U, Klughammer C, Kolbowski J. 2012. Assessment of wavelength-dependent parameters of photosynthetic electron transport with a new type of multi-color PAM chlorophyll fluorometer. Photosynthesis Research 113:127-144. DOI: 10.1007/s11120012-9758-1.

Schuback N, Flecken M, Maldonado MT, Tortell PD. 2016. Diurnal variation in the coupling of photosynthetic electron transport and carbon fixation in iron-limited phytoplankton in the NE subarctic Pacific. Biogeosciences 13:1019-1035. DOI: https://doi.org/10.5194/bg-131019-2016.

Serôdio J, Lavaud J. 2011. A model for describing the light response of the nonphotochemical quenching of chlorophyll fluorescence. Photosynthesis Research 108:61-76. DOI: 10.1007/s11120-011-9654-0.

Siberchicot SD and A, Julien-Laferrière with contributions from JTB on earlier work by A. 2018. adegraphics: An S4 Lattice-Based Package for the Representation of Multivariate Data.

Silsbe GM, Malkin SY. 2015. phytotools: Phytoplankton Production Tools.

Szabó M, Parker K, Guruprasad S, Kuzhiumparambil U, Lilley RMcC, Tamburic B, Schliep M, Larkum AWD, Schreiber U, Raven JA, Ralph PJ. 2014a. Photosynthetic acclimation of Nannochloropsis oculata investigated by multi-wavelength chlorophyll fluorescence analysis. Bioresource Technology 167:521-529. DOI: 10.1016/j.biortech.2014.06.046.

Peer) reviewing PDF | (2020:12:56632:2:0:NEW 22 Jul 2021) 
1219 Szabó M, Wangpraseurt D, Tamburic B, Larkum AWD, Schreiber U, Suggett DJ, Kühl M, Ralph

1220 PJ. 2014b. Effective light absorption and absolute electron transport rates in the coral

1221 Pocillopora damicornis. Plant Physiology and Biochemistry 83:159-167. DOI:

$1222 \quad$ 10.1016/j.plaphy.2014.07.015.

1223 Talling JF. 1957. The Phytoplankton Population as a Compound Photosynthetic System*. New $1224 \quad$ Phytologist 56:133-149. DOI: 10.1111/j.1469-8137.1957.tb06962.x.

1225 Tamburic B, Szabó M, Tran N-AT, Larkum AWD, Suggett DJ, Ralph PJ. 2014. Action spectra of 1226 oxygen production and chlorophyll a fluorescence in the green microalga Nannochloropsis oculata. Bioresource Technology 169:320-327. DOI: 10.1016/j.biortech.2014.07.008.

1228 Thioulouse J. 1987. Les analyses multitableaux en écologie factorielle. :20.

1229 Valle KC, Nymark M, Aamot I, Hancke K, Winge P, Andresen K, Johnsen G, Brembu T, Bones AM. 2014. System Responses to Equal Doses of Photosynthetically Usable Radiation of Blue, Green, and Red Light in the Marine Diatom Phaeodactylum tricornutum. PLoS ONE

Van Leeuwen S, Tett P, Mills D, Molen J van der. 2015. Stratified and nonstratified areas in the North Sea: Long-term variability and biological and policy implications. Journal of Geophysical Research: Oceans 120:4670-4686. DOI: 10.1002/2014JC010485.

1236 Vantrepotte V, Brunet C, Mériaux X, Lécuyer E, Vellucci V, Santer R. 2007. Bio-optical properties of coastal waters in the Eastern English Channel. Estuarine, Coastal and Shelf Science 72:201-212. DOI: 10.1016/j.ecss.2006.10.016.

Wang L, Cai Q, Xu Y, Kong L, Tan L, Zhang M. 2011. Weekly dynamics of phytoplankton functional groups under high water level fluctuations in a subtropical reservoir-bay. Aquatic Ecology 45:197-212. DOI: 10.1007/s10452-010-9346-4. 


\section{Table $\mathbf{1}$ (on next page)}

Abbreviations and definitions.

Abbreviations and definitions of variable fluorescence measurements and photosynthetic parameters (in relative and absolute units) used in the study. 


\begin{tabular}{|c|c|c|}
\hline Abbreviation & Definition & Unit \\
\hline$r . \alpha$ & Maximum light-use efficiency & Electrons quanta $^{-1}$ \\
\hline$\alpha(\mathrm{II})$ & $\alpha$ related to absolute absorption of PSII & Electrons quanta $^{-1}$ \\
\hline CCA & $\begin{array}{l}\text { Complementary Chromatic Adaptation (Kehoe \& Guty, } \\
\text { 2006) }\end{array}$ & unitless \\
\hline CDOM & Colored Disolved Organic Matter & not reported here \\
\hline DIN & Dissolved Inorganic Nitrogen & $\mu \mathrm{mol} \mathrm{L}^{-1}$ \\
\hline $\mathbf{E C}$ & English Channel & unitless \\
\hline $\mathbf{E}_{\mathrm{k}}$ & Light saturation coefficient & quanta $\mathrm{m}^{-2} \mathrm{~s}^{-1}$ \\
\hline $\mathbf{E}_{\mathrm{k}}(\mathrm{II})$ & $E_{k}$ related to absolute absorption of PSII & quanta(PS II s) $)^{-1}$ \\
\hline $\mathbf{E}_{\text {op }}$ & PAR at $\mathrm{ETR}_{\max }$ & $\mu \mathrm{mol}$ quanta $\mathrm{m}^{-2} \mathrm{~s}^{-1}$ \\
\hline $\mathbf{E}_{\text {op }}$ (II) & PAR at $\mathrm{ETR}_{\max }(\mathrm{II})$ & quanta(PS II s) $)^{-1}$ \\
\hline $\mathbf{E}_{\text {avg }}$ & Vertically averaged light intensity & $\mu \mathrm{mol}$ quanta $\mathrm{m}^{-2} \mathrm{~s}^{-1}$ \\
\hline ETR(II) & ETR related to absolute absorption of PSII & electrons(PS II s) $)^{-1}$ \\
\hline r.ETR $\max$ & Maximum electron transport rate & $\mu \mathrm{mol}$ electrons $\mathrm{m}^{-2} \mathrm{~s}^{-1}$ \\
\hline $\mathbf{E T R}_{\max }(\mathrm{II})$ & ETR $_{\max }$ related to absoluted absorption of PSII & electrons(PS II s) ${ }^{-1}$ \\
\hline FCP & $\begin{array}{l}\text { Fucoxanthin-chlorophyll a/c-binding antenna pigment- } \\
\text { protein complex of diatoms }\end{array}$ & unitless \\
\hline $\mathbf{F}_{\mathbf{v}} / \mathbf{F}_{\mathbf{m}}$ & $\begin{array}{l}\text { Maximum quantum yield of PSII determined after } 2.5 \mathrm{~h} \\
\text { of dark acclimation }\end{array}$ & unitless \\
\hline $\mathbf{K}_{\mathrm{d}(\mathbf{P A R})}$ & $\begin{array}{l}\text { PAR extinction coefficient also known as diffuse } \\
\text { attenuation coefficient }\end{array}$ & $\mathrm{m}^{-1}$ \\
\hline $\mathbf{O}-\mathbf{I}_{1}$ & $\begin{array}{c}\text { Photochemical phase of fast fluorescence rise } \\
\text { (Schreiber, 2004) }\end{array}$ & unitless \\
\hline NPQ & Non-photochemical fluorescence quenching ( & unitless \\
\hline$N_{P Q} Q_{1200}$ & $\begin{array}{l}\text { NPQ calculated from fitted NPQ vs. PAR curves at } \\
\text { PAR }=1200 \mu \text { mol electrons } \mathrm{m}^{-2} \mathrm{~s}^{-1}\end{array}$ & unitless \\
\hline $\mathbf{N P Q}_{300}$ & $\begin{array}{l}\text { NPQ calculated from fitted NPQ vs. PAR curves at } \\
\text { PAR }=300 \mu \text { mol electrons } \mathrm{m}^{-2} \mathrm{~s}^{-1}\end{array}$ & unitless \\
\hline PAR & Photosynthetically active radiation & $\mu \mathrm{mol}$ quanta $\mathrm{m}^{-2} \mathrm{~s}^{-1}$ \\
\hline PE curve & Production vs. Irradiance(Energy) curve & unitless \\
\hline PET & Photosynthetic electron transport & unitless \\
\hline$\rho \max$ & $\begin{array}{l}\text { General acronym for light-saturated maximum rate from } \\
\text { PE curve }\end{array}$ & Not reported here \\
\hline PSII & Photosystem II & unitless \\
\hline r.ETR & Relative electron transport rate & $\mu \mathrm{mol}$ electrons $\mathrm{m}^{-2} \mathrm{~s}^{-1}$ \\
\hline $\operatorname{Sigma}(I I)_{\lambda}$ & Wavelength-dependent cross section of PSII & $\mathrm{nm}^{2}$ \\
\hline TSS & Time since sunrise & $\mathrm{h}$ \\
\hline Y(II) & Effective quantum yield of PSII & unitless \\
\hline $\mathbf{Z}_{\mathrm{eu}}$ & Depth of the euphotic layer & $\mathrm{m}$ \\
\hline Zumixl & Depth of the upper mixed layer & $\mathrm{m}$ \\
\hline
\end{tabular}




\section{Table 2 (on next page)}

Statistical outputs of the linear mixed-effects models.

Results of the linear mixed-effects models for photosynthetic parameters (see Table 1 for definitions): best estimates of standard error and significance (for fixed effects) and the significance of individual variation (for random effects). Hypothesis tests were based on ttests (for the intercept and slope of fixed effects), likelihood-ratio tests and the p-value based on $\chi 2$ statistics (for random effects). Significance codes: *** $p<0.00, * * p<0.01, * p<0.05$, ns: non-significant. 


\begin{tabular}{|c|c|c|c|c|c|c|}
\hline \multirow[b]{2}{*}{ Parameters } & \multicolumn{4}{|c|}{ Fixed effects } & \multicolumn{2}{|c|}{ Random effects } \\
\hline & Intercept & Std. Errors & Slope & Std. Error & Intercept & Slope \\
\hline$\overline{\mathbf{F}_{\mathrm{V}} / \mathbf{F}_{\mathrm{m}}}$ & $0.61^{* * *}$ & 0.01 & $-0.00012^{* * *}$ & 0.00002 & $* * *$ & ns \\
\hline $\operatorname{Sigma}(I I)_{\lambda}$ & $6.08^{* * *}$ & 0.03 & $-0.0241^{* * *}$ & 0.0011 & $* *$ & $\mathrm{~ns}$ \\
\hline r.ETR ${ }_{\max }$ & $41.19^{* * *}$ & 5.26 & $0.44^{* * *}$ & 0.04 & $* * *$ & $* * *$ \\
\hline $\mathbf{E T R}_{\max }(\mathrm{II})$ & $527.42^{* * *}$ & 35.84 & $-0.09 \mathrm{~ns}$ & 0.20 & $* * *$ & $*$ \\
\hline$r . \alpha$ & $0.21^{* * *}$ & 0.007 & $0.00029^{* * *}$ & 0.00004 & $* * *$ & ns \\
\hline$\alpha(I I)$ & $0.57^{* * *}$ & 0.03 & $0.0015^{* * *}$ & 0.0001 & $* * *$ & ns \\
\hline $\mathbf{r .} \mathbf{E}_{\mathrm{k}}$ & $200.94^{* * *}$ & 21.78 & $1.39^{* * *}$ & 0.12 & $* * *$ & $* *$ \\
\hline $\mathbf{E}_{\mathrm{k}}(\mathrm{II})$ & $905.92^{* * *}$ & 43.81 & $-1.72^{* * *}$ & 0.32 & $* * *$ & $* *$ \\
\hline $\mathbf{r} . \mathrm{E}_{\mathrm{op}}$ & $1998.90^{* * *}$ & 141.01 & $-1.69^{n s}$ & 0.90 & $* * *$ & ns \\
\hline $\mathrm{E}_{\mathrm{op}}(\mathrm{II})$ & $5737.18^{* * *}$ & 405.36 & $-18.43^{* * *}$ & 2.44 & $* * *$ & ns \\
\hline $\mathbf{N P Q}_{\mathbf{3 0 0}}$ & $0.90^{* * *}$ & 0.06 & $-0.004^{* * *}$ & 0.0003 & $* * *$ & $\mathrm{~ns}$ \\
\hline $\mathbf{N P Q _ { 1 2 0 0 }}$ & $1.94^{* * *}$ & 0.111 & $-0.006^{* * *}$ & 0.0004 & $* * *$ & ns \\
\hline
\end{tabular}




\section{Table 3(on next page)}

Statistical outputs of each K-tables in partial triadic analysis (PTA).

Vector correlation coefficients between the submatrix of photosynthetic parameters at each wavelength $(\mathrm{nm})$, their weights in partial triadic analysis and $\cos ^{2}$. 


\begin{tabular}{llllllll}
\hline Wavelength & $\mathbf{4 4 0}$ & $\mathbf{4 8 0}$ & $\mathbf{5 4 0}$ & $\mathbf{5 9 0}$ & $\mathbf{6 2 5}$ & Weight $^{\text {cos }^{2}}$ \\
\hline $\mathbf{4 4 0}$ & 1.00 & 0.88 & 0.74 & 0.50 & 0.59 & 0.47 & 0.91 \\
$\mathbf{4 8 0}$ & & 1.00 & 0.77 & 0.43 & 0.60 & 0.47 & 0.90 \\
$\mathbf{5 4 0}$ & & & 1.00 & 0.54 & 0.69 & 0.47 & 0.89 \\
$\mathbf{5 9 0}$ & & & & 1.00 & 0.61 & 0.38 & 0.69 \\
$\mathbf{6 2 4}$ & & & & & 1.00 & 0.44 & 0.80 \\
\hline
\end{tabular}

1 


\section{Table 4(on next page)}

Total inertia of partial triadic analysis (PTA) compromise analyses.

Total inertia of partial triadic analysis (PTA) compromise analyses, cumulative inertia of each

PTA axis (Cum) and percentage of cumulative total inertia (Cum \%). 


\begin{tabular}{llll}
\hline Axe & Inertia & Cum & Cum (\%) \\
\hline $\mathbf{1}$ & 10.56 & 10.56 & 37.76 \\
$\mathbf{2}$ & 8.54 & 19.10 & 66.49 \\
$\mathbf{3}$ & 4.51 & 23.61 & 82.18 \\
$\mathbf{4}$ & 2.42 & 26.03 & 90.61 \\
\hline
\end{tabular}

1 


\section{Table 5 (on next page)}

Results of redundancy analysis (RDA) of detrended photosynthetic parameters at each wavelength.

Forward-selected explanatory variables of RDA model, explained and residual variances, the adjusted $R^{2}$ and associated $p$-value for abiotic ( $Z_{\text {eu }}$ (euphotic layer), TSS (Time since sunrise), $\mathrm{K}_{\mathrm{d}(\mathrm{PAR})}$ (downwelling diffuse attenuation coefficient of underwater light), DIN (of dissolved inorganic nitrogen, i.e. $\mathrm{NO}_{3}+\mathrm{NO}_{2}$ ) and $\mathrm{G} / \mathrm{R}$ (Green/Red light quality ratio)) and biotic variables. No biotic variable was selected, and the model for the red wavelength ( $625 \mathrm{~nm}$ ) was not significant. Significance codes: $* * * p<0.00, * * p<0.01$, ns: non-significant. 


\begin{tabular}{llll|ll|ll}
\hline & & \multirow{2}{*}{ Varianc } & Residual & \multicolumn{2}{c|}{ Abiotic } & \multicolumn{2}{c}{ Biotic } \\
Wavelength & Model & $\mathbf{e}$ & variance & adj R & $\mathbf{p}$ & adj R & p \\
\hline 440 & $\mathrm{Z}_{\mathrm{eu}}$ & 1.60 & 6.40 & 0.15 & $* *$ & 0.023 & $\mathrm{~ns}$ \\
480 & $\mathrm{Z}_{\mathrm{eu}}+\mathrm{TSS}+\mathrm{K}_{\mathrm{d}(\mathrm{PAR})}+\mathrm{DIN}$ & 4.16 & 3.82 & 0.38 & $* * *$ & -0.001 & $\mathrm{~ns}$ \\
540 & $\mathrm{Z}_{\mathrm{eu}}$ & 2.35 & 5.65 & 0.20 & $* *$ & 0.010 & $\mathrm{~ns}$ \\
590 & $\mathrm{TSS}+\mathrm{G} / \mathrm{R}$ & 2.57 & 5.42 & 0.23 & $* *$ & 0.05 & $\mathrm{~ns}$ \\
625 & None & 6.00 & 1.99 & 0.10 & $\mathrm{~ns}$ & -0.111 & $\mathrm{~ns}$ \\
\hline
\end{tabular}

1 
Figure 1

Sampling locations.

Sampling locations ( $n=19$ among 55 locations sampled) for the study of phytoplankton wavelength dependence in the English Channel during the ECOPEL campaign in April 2018.

The framed station numbers refer to thermal and haline stratified water columns.

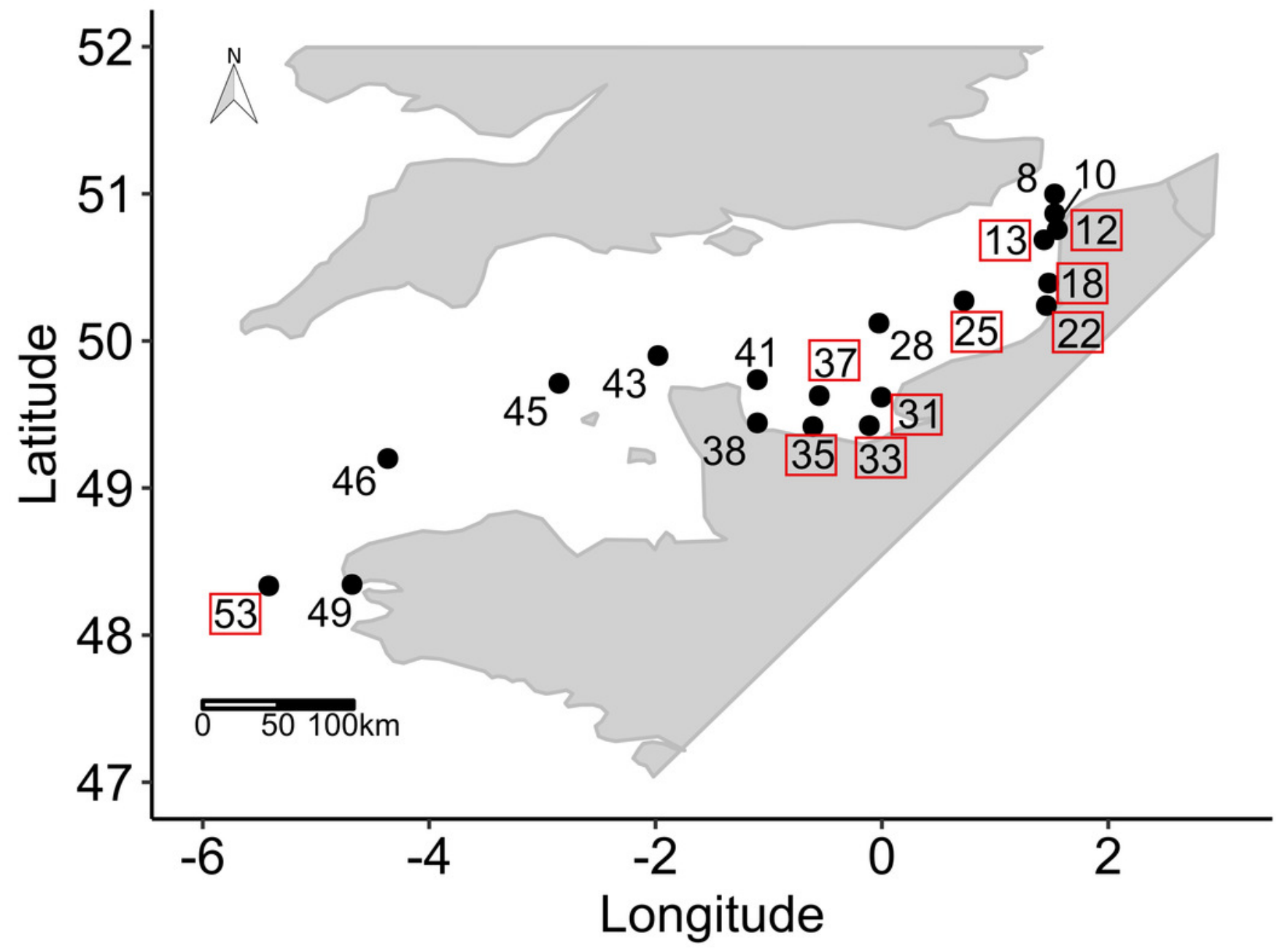


Figure 2

Original methodological approach diagram.

Diagram of the three-step numerical method used after fitting the electron transport rate (ETR) vs. photosynthetically active radiation (PAR) curve: linear mixed-effects models, partial triadic analysis and redundancy analysis. 


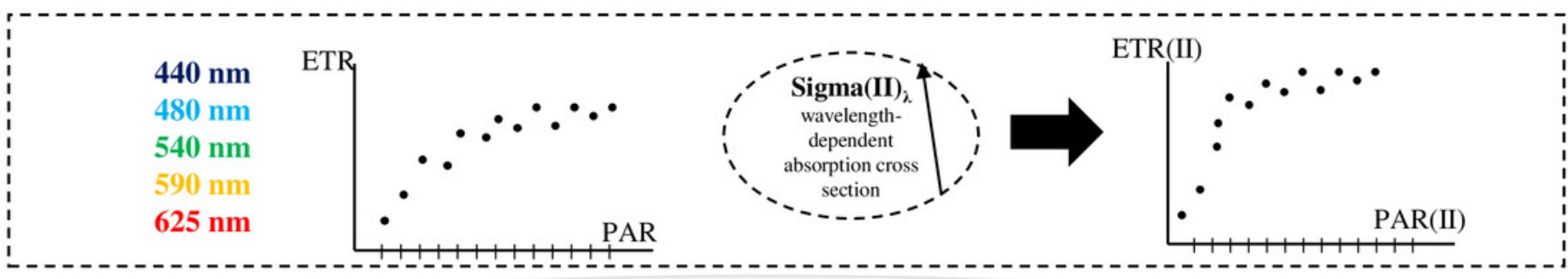

Fitting ETR vs. E (“phytotools” package) and NPQ vs. E

$\downarrow$

STEP 1: ANALYSIS OF WAVELENGTH-DEPENDENCY OF PHOTOSYNTHESIS

LINEAR MIXED EFFECTS MODELS (LMEM)

"Imer" function of the "Ime4" package

FIXED EFFECTS:

Population mean wavelength-dependenc:

Mean tendency of each photosynthetic parameter

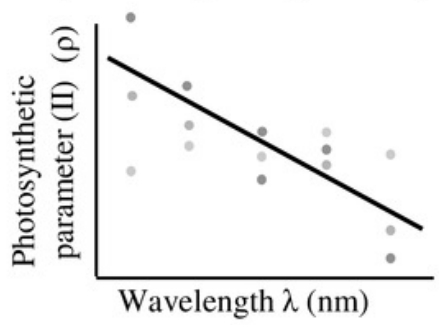

RANDOM EFFECTS:

Individual photoacclimation expression: Variance of wavelength tendency

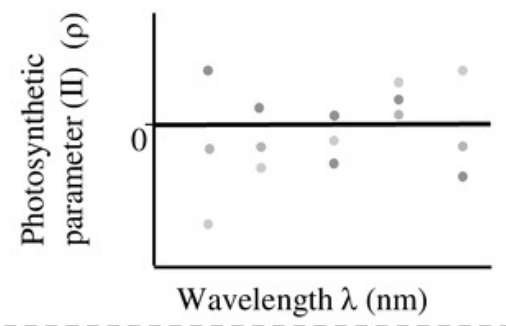

\section{STEP 2: ANALYSIS OF INDIVIDUAL DETRENDED VARIATION OF PHOTOSYNTHESIS}

\section{PARTIAL TRIADIC ANALYSIS (PTA)}

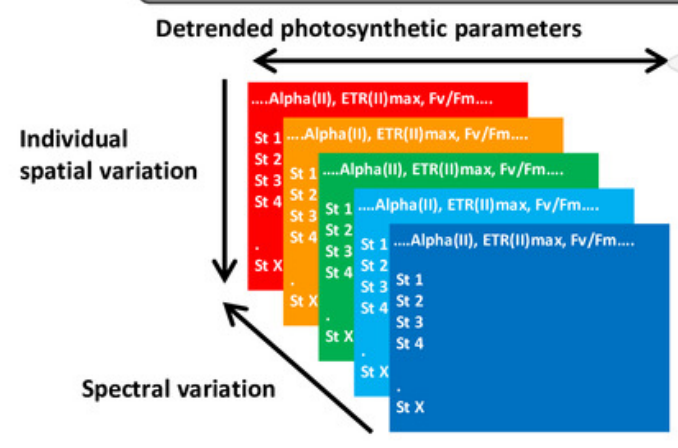

"withinpca"; "ktab.whin"; "pta" funtions of "ade4" package

\section{INTERSTRUCTURE}

Wavelength-dependent typology of samples

\section{COMPROMISE}

The same structure of samples and parameters

INTRASTRUCTURE

Differences from the compromise structure

\section{STEP 3: DEFINITION OF CONTROLLING FACTORS OF SPECTRAL VARIANCE}

\section{REDUNDANCY ANALYSIS (RDA)}

\section{Detrended photosynthetic parameters}

BIOTIC: no significant effect

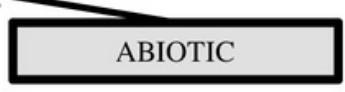

"rda" function of the "vegan" package

"ordiR2step" function of the "vegan" package. Forward selection of significant variables 
Figure 3

Principal component analysis (PCA) of abiotic and biotic variables.

The first two axes of the Principal Component Analyses (PCA) performed on: A) abiotic variables and $B$ ) biotic variables (biomass of the four phytoplankton groups determinated by the bbe fluoroprobe), considering the 19 sampling stations. The \% of explained variance for each axes is specified. The contribution (contrib) of each variable is indicated by a gray color scaling.
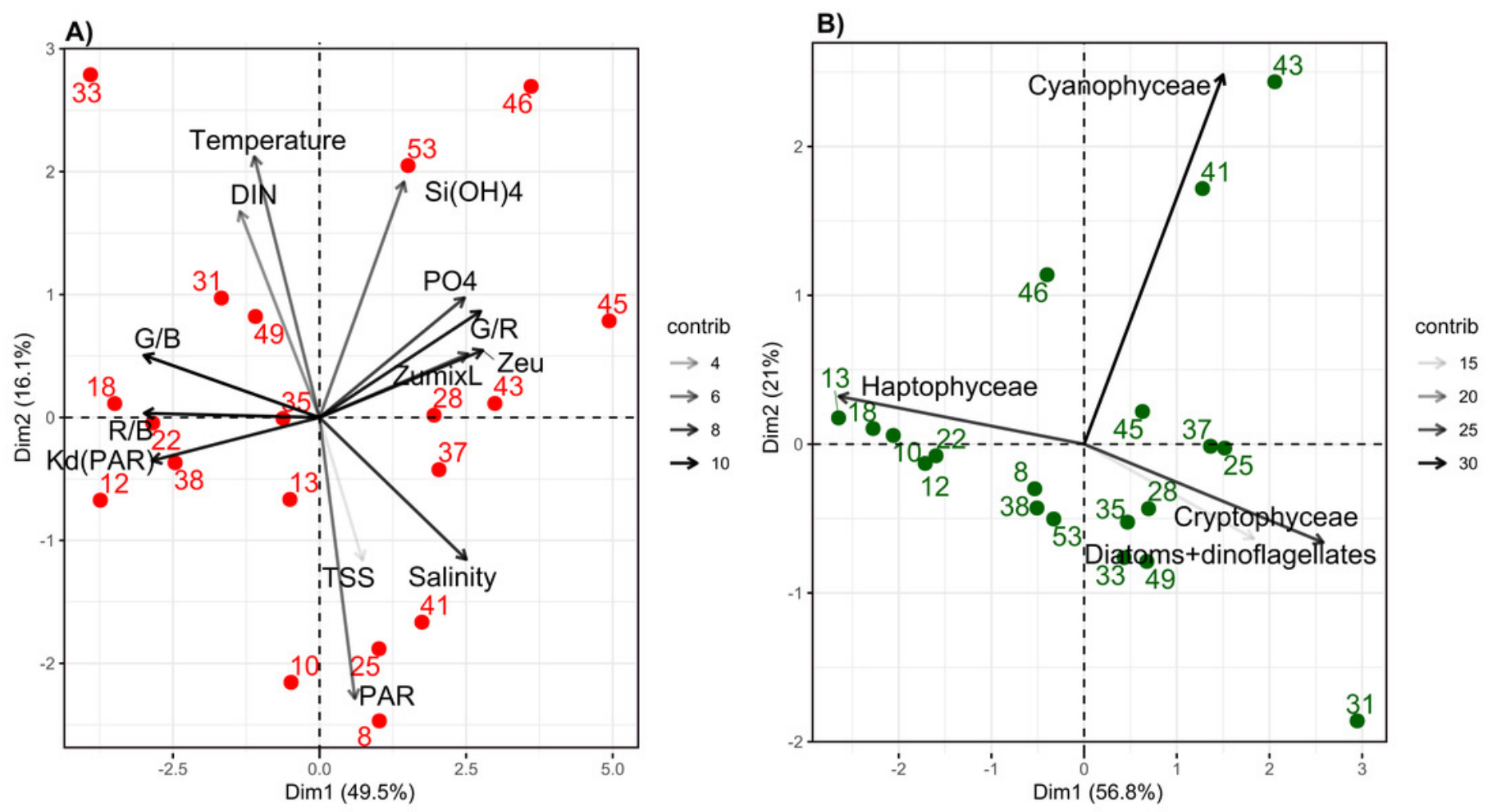
Figure 4

Raw data of each photosynthetic parameters.

Raw data of each photosynthetic parameter (see Table 1 for definitions) of the 19 samples by wavelength and the fixed effect (red line) of linear mixed-effect models (i.e. wavelength dependence at the population level). 

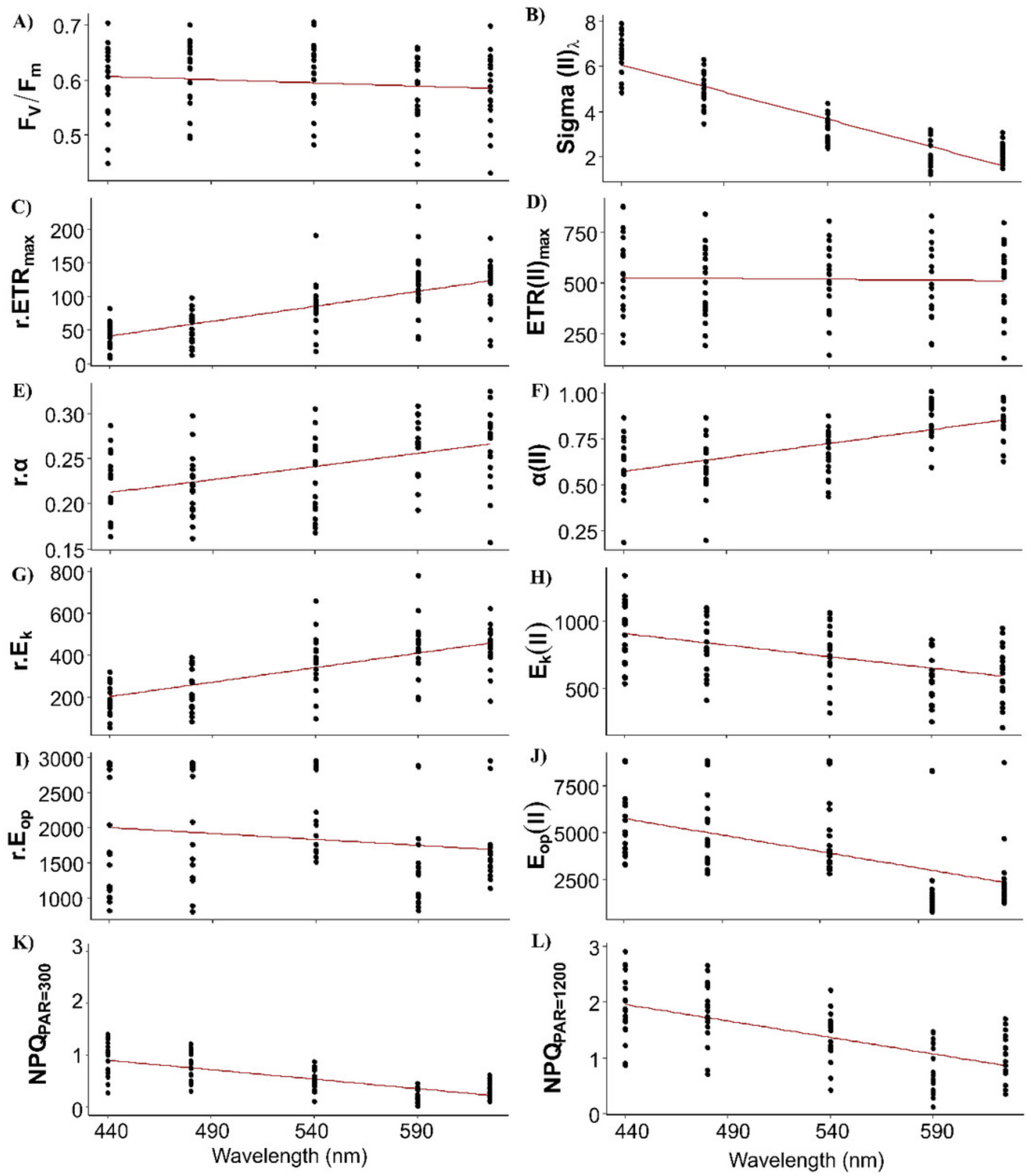


\section{Figure 5}

Detrended spectral photosynthetic parameters.

Detrended spectral photosynthetic parameters (Table 1 for definitions) resulted by calculating individual differences from the population trend (the linear mixed-effect models) among sampling locations. Point colors indicate each of the five wavelengths analyzed: 440, $480,50,590$ and $625 \mathrm{~nm}$. 


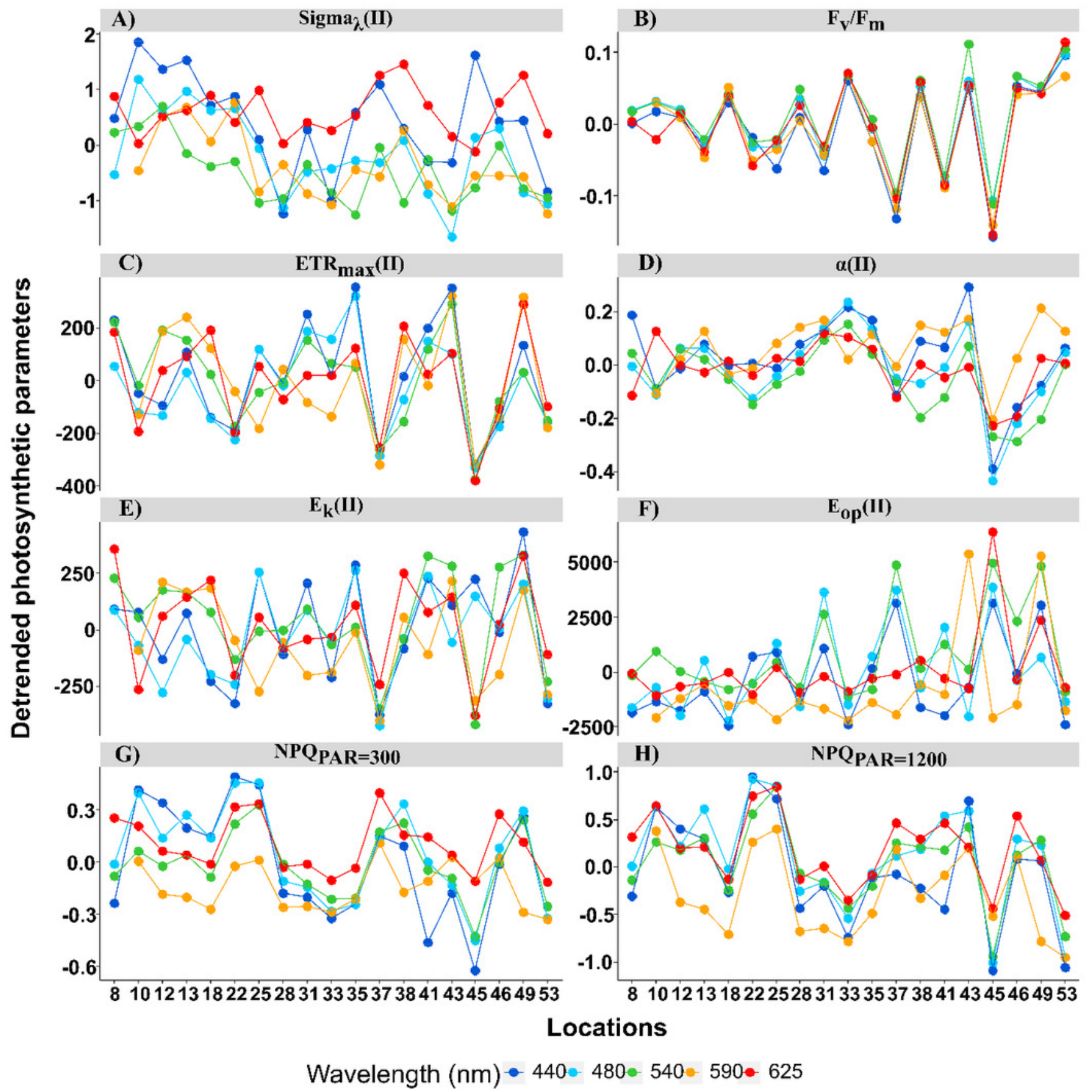




\section{Figure 6}

Intrastructure results of detrended photosynthetic parameters of Partial Triadic Analysis.

Results of intrastructure of the partial triadic analysis of detrended photosynthetic parameters $\operatorname{ETR}_{\max }(\mathrm{II}), \mathrm{E}_{\mathrm{k}}, \mathrm{Alpha}(\mathrm{II}), \mathrm{E}_{\mathrm{op}}(\mathrm{II})$, Sigma(II), $\mathrm{Fv} / \mathrm{Fm}$ and NPQ (see Table 1 for definitions) at 300 and $1200 \mu \mathrm{mol} \cdot$ photons $\cdot \mathrm{m}^{-2} \mathrm{~s}^{-1}$ ) projected on compromise coordinates (A). Each photosynthetic parameters coordinate is represented separately for each wavelength at 440 (B), $480 \mathrm{~nm}$ (C), 540 (D), 590 (E) and 625 (F) nm. See Table 3 for compromise contribution to total inertia and Table 4 for weight and $\cos ^{2}$ of each of the wavelengths colors in PTA analysis. 

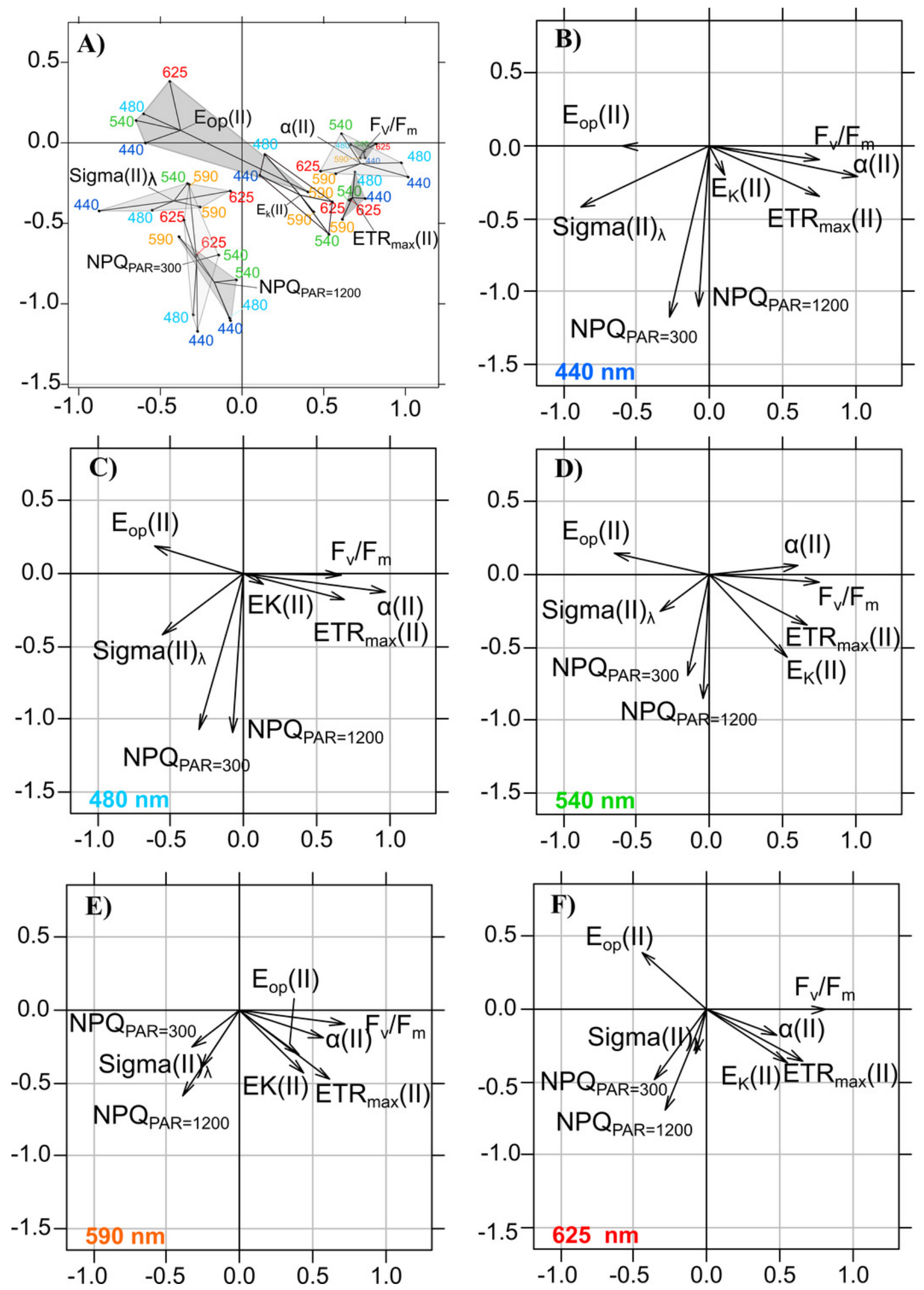


\section{Figure 7}

Intrastructure results of partial triadic analysis (PTA) for each location.

Partial triadic analysis intrastructure (first and second dimension) projected on compromise coordinates of photosynthetic parameters for each of the 18 locations: factorial map of spectral responses projected on compromise coordinates for each sample. The dotted line in the first figure represents the coordinates used to represent samples 12, 13, 18, 38, 41 and 49 separately to improve visualization of this part of the factorial map. 

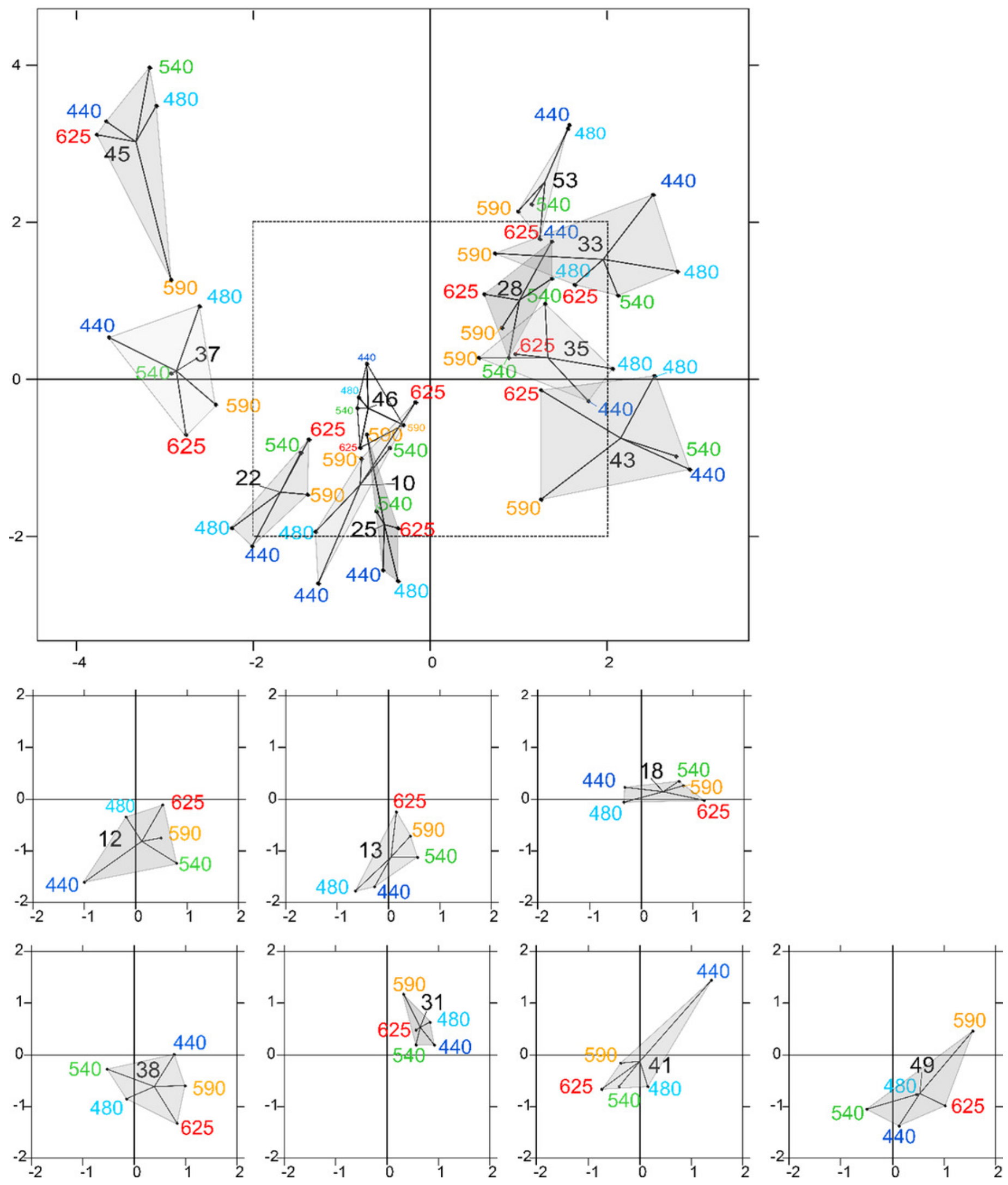


\section{Figure 8}

Relationships between photoacclimation indexes and physical parameters.

Relationships between (A) the $E_{k, 440} / E_{\text {avg }}$ ratio (the photoacclimation index measured at 440 $\mathrm{nm}$ to the vertically averaged PAR light intensity) (in relative ( $\mathrm{r}$ ) and absolute (II) units) and the $Z_{\text {eu }} / Z_{\text {uml }}$ ratio (depth of the euphotic layer to that of the upper mixed layer) and (B) between $E_{k}(I I)_{(625 / 440)}$ (ratio of photoacclimation index measured at red and blue wavelengths) and the corresponding red/blue wavelength ratios of light $\left(\mathrm{E}_{(625 / 400)}\right)$ in water masses for the 19 locations. The regression equation in $B$ is $y=0.5789 x+0.2516(F=5.62 ; p=0.0298)$. Pearson correlation coefficients, level of significance $(* p<0.05)$ and the number of considered data are also reported on each graph. 

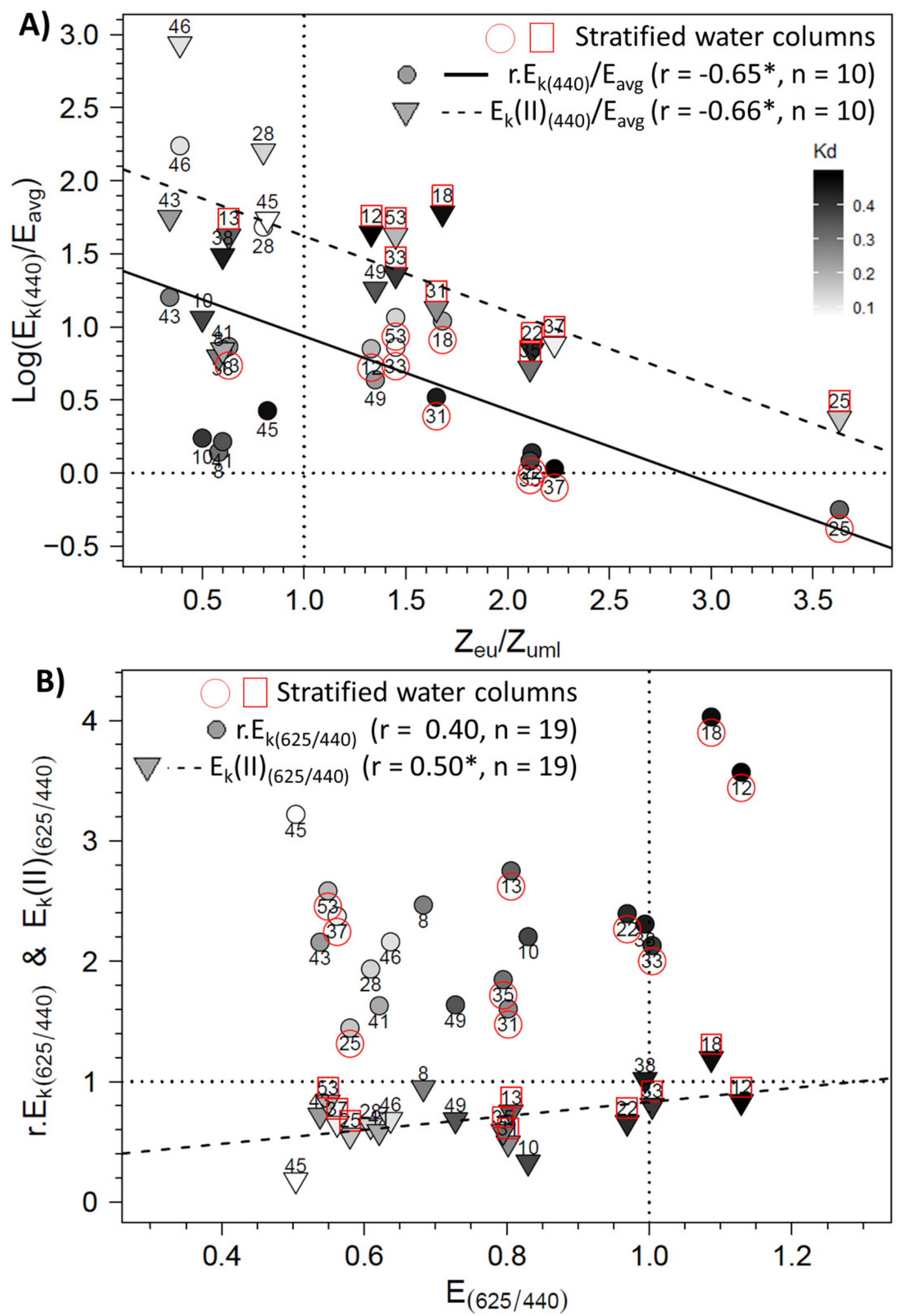